The economics of adaptation and climateresilient development: lessons from projects for key adaptation challenges

Paul Watkiss and Federica Cimato

May 2016

Centre for Climate Change Economics and Policy Working Paper No. 265

Grantham Research Institute on Climate Change and the Environment

Working Paper No. 235 
The Centre for Climate Change Economics and Policy (CCCEP) was established by the University of Leeds and the London School of Economics and Political Science in 2008 to advance public and private action on climate change through innovative, rigorous research. The Centre is funded by the UK Economic and Social Research Council. Its second phase started in 2013 and there are five integrated research themes:

1. Understanding green growth and climate-compatible development

2. Advancing climate finance and investment

3. Evaluating the performance of climate policies

4. Managing climate risks and uncertainties and strengthening climate services

5. Enabling rapid transitions in mitigation and adaptation

More information about the Centre for Climate Change Economics and Policy can be found at: http://www.cccep.ac.uk.

The Grantham Research Institute on Climate Change and the Environment was established by the London School of Economics and Political Science in 2008 to bring together international expertise on economics, finance, geography, the environment, international development and political economy to create a worldleading centre for policy-relevant research and training. The Institute is funded by the Grantham Foundation for the Protection of the Environment and the Global Green Growth Institute. It has nine research programmes:

1. Adaptation and development

2. Carbon trading and finance

3. Ecosystems, resources and the natural environment

4. Energy, technology and trade

5. Future generations and social justice

6. Growth and the economy

7. International environmental negotiations

8. Modelling and decision making

9. Private sector adaptation, risk and insurance

More information about the Grantham Research Institute on Climate Change and the Environment can be found at: http://www.Ise.ac.uk/grantham.

\section{Canada's International Development Research Centre (IDRC)}

A key part of Canada's foreign policy efforts, IDRC supports research in developing countries to promote growth and development. The result is innovative, lasting solutions that aim to improve lives and livelihoods. www.idrc.ca.

This working paper is intended to stimulate discussion within the research community and among users of research, and its content may have been submitted for publication in academic journals. It has been reviewed by at least one internal referee before publication. The views expressed in this paper represent those of the author(s) and do not necessarily represent those of the host institutions or funders. 


\title{
The Economics of Adaptation and Climate-Resilient Development: Lessons from Projects for Key Adaptation Challenges *
}

\author{
Paul Watkiss and Federica Cimato
}

\section{EXECUTIVE SUMMARY}

This working paper aims to inform the development community about the current state-of-knowledge and emerging thinking on the economics of adaptation and the application to development. The paper explores a number of key challenges on the economics of adaptation, and investigates examples of how these are being addressed in practical case studies. The case studies are drawn from the portfolio of the International Development Research Centre (IDRC) and the wider literature. The key areas of focus have been to assess:

- Mainstreaming adaptation into development planning.

- The analysis and appraisal of building (adaptive) capacity and non-technical adaptation.

- The consideration of distributional effects.

- The phasing and prioritisation of adaptation and the application of light-touch approaches for decision making under uncertainty.

The analysis has first considered the mainstreaming of adaptation, recognising the recent emphasis on integrating (mainstreaming) adaptation into current policy and development, rather than implementing measures as a stand-alone activity. This requires the integration of adaptation into existing policies and processes, taking account of broader policy objectives and wider costs and benefits, not just for climate change. The review and case studies provide a number of additional insights. Effective mainstreaming requires the identification of suitable entry points in the policy and development planning process, noting these will differ across sectors and national contexts. An evaluation of case studies has been undertaken, focusing on LDCs where mainstreaming is being advanced. These indicate that the presence of a high level champion, the involvement of strong Ministries, the availability of climate finance and, technical assistance and capacity building support are important in effectively advancing mainstreaming. There is a need for pragmatism when mainstreaming and success will often be contingent on the timing of action and the ability to take advantage of intervention opportunities. A critical finding is that there is a strong need for technical assistance and capacity building to enable mainstreaming to occur. This remains an emerging area, and further practical orientated research and support is needed.

The second area of interest has explored the analysis and appraisal of efforts to build (adaptive) capacity. This follows the recent adaptation literature which has moved from a focus primarily on technical options to a more comprehensive set of interventions that include capacity building, institutional strengthening, research and information, as well as non-technical (soft) options. These options are widely recommended as early low-regret priorities. Underpinning this shift is the recognition that adaptation is a process, which requires adaptive or organisational capacity, and that there are important barriers to adaptation that need to be addressed to enable effective implementation. However, it is particularly challenging to appraise capacity building and institutional/organisational options in quantitative economic appraisal and the study has investigated the analysis of these options, looking at the type and timing of their costs and benefits. Some of these options can be quantified using the value of information, for both early direct responses, and for informing future orientated decisions, although these involve different aspects due to the temporal 
scales. There are also approaches for assessing socio-institutional and organisational options, though most of the literature applies qualitative assessments. A review of the case studies and the wider literature has found a number of good practice examples. These show that appraisal is possible, and these options produce high benefit to cost ratios, though these are dependent on assumptions about the results chain. An analysis of the lessons and information in the literature and case studies reveals important issues - about the economic appraisal of these options - but also more widely how to design effective capacity building and institutional support: these provide valuable lessons for the adaptation domain. Given these areas are a priority in the IDRC portfolio (for adaptation and more broadly), further ex ante and ex post analysis of the portfolio is recommended.

The third area has investigated the potential methodological issues with the distributional analysis of climate change and adaptation. Climate change disproportionately impacts poor and vulnerable groups and a key issue is whether these differences are taken into account when assessing climate risks and designing adaptation interventions. A review of the evidence base on climate change impacts and adaptation, especially of the economic literature, reveals this issue has been qualitatively recognised, but with little quantitative consideration, and it has not - to date- been integrated into adaptation plans and appraisal. This reflects a broader trend in the development literature: potential approaches (such as distributional weights) to address such issues do exist, but these are rarely used in economic appraisal. A more common practice is to consider the distributional effects of policies or projects qualitatively. A review of the IDRC portfolio and other studies has found a number of good practice examples, where these types of qualitative approaches have been used. These provide some key lessons and identify areas for future research. The future consideration of these distributional issues - in both risk assessment and adaptation design - is highlighted as a priority for future adaptation assessment and policy applications.

The final area of the analysis has focused down on the prioritisation of adaptation and the application of light-touch approaches for decision making uncertainty. With the greater focus on adaptation implementation - and the emerging climate finance to fund this - there is an increasing need to prioritise adaptation. There are two key stages where this is relevant: at the scoping phase and in detailed appraisal. While there are routine methods for both of these, there are a number of additional challenges for adaptation. In the scoping phase, a key issue concerns the short-listing of options: this can be advanced by considering the timing and phasing of adaptation. An analysis of the IDRC portfolio and other literature provides some case studies on such approaches. In the detailed appraisal phase, a key challenge is the high uncertainty involved. The most common techniques used in economic appraisal have limitations in addressing this, and a suite of new decision support tools have emerged that advance decision-making under uncertainty. However, these approaches are complex to use and have high capacity and resources, which are a barrier to their application in more routine project appraisal. A key priority is thus to develop more pragmatic (light-touch) versions of these methods, which can capture core concepts of decision making under uncertainty while maintaining a degree of economic rigour. An analysis of the IDRC portfolio and other literature provides some case studies of these. Future work to advance and to demonstrate these light-touch approaches is needed, especially if these can be integrated into the more policy orientated and climate finance proposals. This is identified as a future priority, noting that there is an issue to develop these methods specifically for developing countries.

The report concludes with suggested priorities for future research.

*This work was carried out with financial support from Canada's International Development Research Centre (IDRC) through the project on the 'Economics of Adaptation and Climate-Resilient Development'. It also draws on the ECONADAPT project, funded by the European Union's Seventh Framework Programme for research, technological development and demonstration under grant agreement no 603906. The authors are grateful to Alistair Hunt for inputs and Sam Fankhauser for comments and feedback. 


\section{Table of Contents}

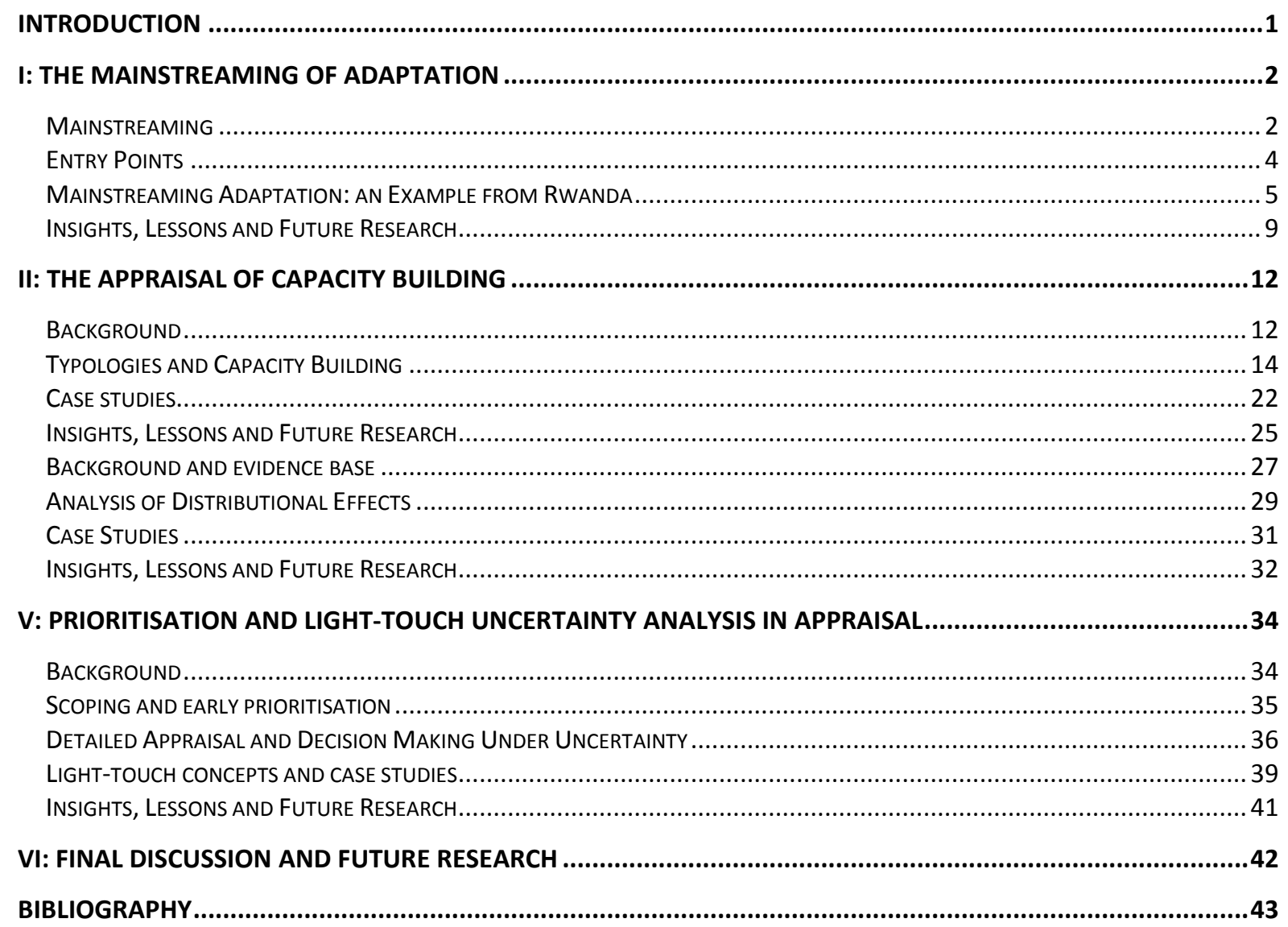




\section{Introduction}

This working paper aims to inform the development community about the current state-of-knowledge and emerging thinking on the economics of adaptation and its application to development. It follows on from an earlier working paper (Watkiss, 2015) that undertook a review for five key themes exploring the methods and framing for the analysis of adaptation, the types of adaptation applications and relevant economic support, and update of estimates of the costs and benefits of adaptation, methodological aspects of adaptation appraisal and analysis of uncertainty in adaptation appraisal. Following from this initial phase, this paper looks in more detail at key issues that were identified in the earlier review for further investigation.

- The mainstreaming adaptation into development planning.

- The analysis and appraisal of building (adaptive) capacity.

- The consideration and treatment of distributional effects.

- The phasing and prioritisation of adaptation and the application of light-touch approaches for decision making under uncertainty.

For each of these, a more detailed review of these areas has been undertaken - together with a lighttouch assessment of existing studies that provide useful examples and lessons of good practice. The analysis has included studies on the economics of climate change funded by the International Development Research Centre (IDRC) as well as a selection of case studies across the wider IDRC portfolio. ${ }^{1}$ It has also drawn on the wider literature on the economics of adaptation (see ECONADAPT, 2015).

\footnotetext{
${ }^{1}$ This includes the studies of: Acevedo (2014); Adhikari (2003); Ahmad, Siftain and Iqbal (2014); Ahmad, Nawaz, Iqbal and Javed (2014); Balasubramian and Selvaraj (2003); Bayani-Arias et al (2013); Catwright et al. (2013); Chen et al (2013); Dasgupter; et al (2015); Dehlavi et al. (2015): Escobar, Torres and Cabrera; Garcia Lopez and Tomás 2015); Huang et al. (2015); Huang, and Wang (2014); Javed et al. (2014); Lunduka et al. (2012); Madrigal-Ballestero and Naranjo (2013); Nyda, Hoeurn and Naret (2013); Pacay et al.; Rios et al. (2014); Roy (2007); Thampanishvong (2015); Bui Dung The (2014); Bui Dung The and Bui Duc Tinh (2014); Wang et al. (2013); Want et al. (2014); Wang et al. (2015).
} 


\section{I: The Mainstreaming of Adaptation}

Key findings:

- There is an increasing emphasis on integrating (mainstreaming) adaptation into current policy and development, rather than implementing measures as a stand-alone activity. This requires the integration of adaptation into existing policies and processes, taking account of broader policy objectives and wider costs and benefits, not only for climate change risks.

- Effective mainstreaming requires the identification of suitable entry points in the policy and development planning process, noting these will differ across sectors and national contexts.

- An evaluation of case studies has been undertaken, focusing on low-income countries where mainstreaming is being advanced. These indicate that the presence of a high level champion, the involvement of strong Ministries, the availability of climate finance and critically, technical assistance and capacity building support are important in effectively advancing mainstreaming.

- There is a need for pragmatism when mainstreaming and success will often be contingent on the timing of action and the ability to take advantage of intervention opportunities. A critical finding is that there is a strong need for technical assistance and capacity building to enable mainstreaming to occur.

- This remains an emerging area, and further practice-orientated research and support is needed.

The earlier review by Watkiss (2015) identified that over recent years there has been a major shift in adaptation assessment - and the economics of adaptation -towards mainstreaming.

This section reports on a more detailed investigation of mainstreaming, and evaluates examples within climate resilient development. It draws on these to provide some insights and key lessons.

\section{Mainstreaming}

While there is still no formal definition of mainstreaming, the term is broadly used interchangeably with 'integration'. Mainstreaming is therefore the integration of adaptation into existing policies and decision-making, rather than the implementation of standalone adaptation policies, plans or measures.

Over recent years, there has been an important shift towards mainstreaming for the assessment of adaptation, particularly at national level. This has been the primary approach in developed countries (as found in a country review by the OECD, 2015) and is increasing in developing countries (UNDP, 2011). The recent National Adaptation Plan (NAPs) guidance also recommends the mainstreaming of adaptation (LDC expert group, 2012)).

The shift towards mainstreaming has arisen as adaptation has moved to implementation, due to the greater focus on immediate actions, and the strong overlap with existing areas of current policy (e.g. water management, sustainable agriculture, disaster risk reduction, etc.), which necessitates greater consistency with existing sector and cross-cutting objectives and interventions (UNDP, 2011). It has become particularly important in developing countries, because the volume of climate finance is increasing strongly (UNDP, 2014) and moving beyond the level of a few individual projects: there is therefore a need to programme this finance through the development planning process to make the 
process manageable and to align it to underlying development objectives. Alongside this, the national and sector development planning process is implementing strategy and plans (non-climate orientated) that will affect or are relevant to climate risks and adaptation, and thus there is a need to consider the inter-play between climate and development. The integration of adaptation into existing policies, plans and processes can address these aspects and enhance harmonisation towards climate resilient development.

Mainstreaming does, however, have a number of important implications.

Many interventions of relevance or that are synergistic with adaptation are often implemented for non-climate reasons, with multiple objectives (Berrang-Ford, 2011). They also require the consideration of other (non-climatic) costs and benefits that are material to the overall choice of intervention. Indeed, in many cases, adaptation will only be one part of the overall policy or decisionand not necessarily the dominant one. As a consequence, it is important to understand the context for an intervention and decision, including the existing policy and objectives, non-climatic drivers, and the current decision-making process. To illustrate, resilience may be mainstreamed as part of an urban regeneration programme, but the design of such a programme will be dominated by local economic development objectives and other drivers, such as demography and land-use change (Watkiss, Benzie and Klein 2015). In this context, mainstreaming aligns closely with the new focus on policy-orientated approaches (discussed in the review phase, and Wilby, 2012).

There is thus a need to consider the socio-institutional factors involved. Implementing adaptation especially against the background of existing policies and objectives - requires a good understanding of the individual organisations, institutional networks and the processes concerning decisions (Berkhout et al, 2006: Moser and Ekstrom, 2010). Critically, all of these will differ with each specific adaptation mainstreaming problem due to the specific existing context.

These issues are especially relevant for developing countries, because these countries have economies that are generally more climate sensitive and they tend to have a high adaptation deficit ${ }^{2}$ (Parry et al, 2009). This also means that existing policy and strategy is more orientated towards climate relevant activities. In addition, they tend to have a shorter-term perspective in relation to development planning, focusing on short-term priorities for growth and poverty reduction. These factors emphasize the need to integrate adaptation into the existing policy and development landscape, to advance climate resilient development.

The concept of mainstreaming - of incorporating an additional factor to the decision process - is however, not new to adaptation. It has been applied across a range of policy areas to address crosscutting issues such as gender, health and environmental impacts and these provide useful experience. For example, in the context of environmental mainstreaming, the OECD (2012) study on greening development highlighted specific interventions including using multi-year development planning processes, developing key actors technical skills, encouraging the participation of non-government actors, and planning and targeting efforts carefully. The study also provided recommendations on how development support can deliver better capacity, highlighting the need to view capacity support for the environment as underpinning all development support, collaborating across domestic agencies, harmonising approaches among development support providers, nurturing local ownership, focusing on results, implementing best practice guidelines, and the need to reflect and learn.

\footnotetext{
2 The IPCCC (2014) defines this as the gap between the current state of a system and a state that minimizes adverse impacts from existing climate conditions and variability. In this study, we use an adjusted definition, which recognises that it is not economically efficient to reduce the adaptation gap to zero (even highly developed countries have an adaptation deficit) and thus the level of adaptation is sub-optimal.
} 
There are, however, some important differences for adaptation when compared to these other areas of mainstreaming (e.g. environment, gender, health, etc.). As highlighted in Watkiss (2015), a number of the characteristics of adaptation present particular challenges for mainstreaming, such as the consideration of future climate change uncertainty. Moreover, there is a particular distinction because of the additional finance that is available for adaptation: this provides the potential for additional funding to fund and help deliver mainstreaming (over and above existing policy), though mainstreaming can potentially be at odds with the need for international development support to demonstrate funding of new and additional activities over and above development (additionality).

\section{Entry Points}

An important component of the mainstreaming process is to find relevant entry points (OECD, 2009: UNDP, 2011), that is, to identify opportunities in the national, sector or project planning process where climate adaptation considerations can best be integrated.

Critically, these entry points differ with the geographical and policy aggregation level, i.e. from national down to local level, and from policy or strategy down to individual projects. They also differ with the sector and type of adaptation problem, noting these may differ between countries or across different sectors within a country. This makes it is essential to understand and integrate adaptation within the existing socio-institutional landscape, especially as adaptation will be one of many policy objectives, and not necessarily the dominant one.

This is illustrated in Figure 1 (from OECD, 2015). Relevant mainstreaming activities are shown on the left side, with decision-making steps on the right. For each level of decision-making, there will be an entry point for mainstreaming adaptation. A critical part of the mainstreaming process is therefore to identify these entry points and to look for opportunities on how best to include adaptation.

\section{Figure 1: Mainstreaming steps and entry points}

\section{Relevant activities Stage in Policy Cycle Decision-making}

\begin{tabular}{|c|c|c|}
\hline & National Strategy & $\begin{array}{l}\text { Strategic level decision making } \\
\text { e.g. creating enabling environment }\end{array}$ \\
\hline $\begin{array}{r}\text { Mainstreaming in national } \\
\text { level policies }\end{array}$ & $\begin{array}{c}\text { National } \\
\text { (Action) Planning }\end{array}$ & $\begin{array}{l}\text { Initial prioritisation of policies } \\
\text { and programmes }\end{array}$ \\
\hline $\begin{array}{r}\text { Mainstreaming in sector } \\
\text { plans }\end{array}$ & $\begin{array}{l}\text { Sector } \\
\text { Planning }\end{array}$ & Impact assessment and prioritisation \\
\hline $\begin{array}{l}\text { Mainstreaming in sector } \\
\text { programmes or projects }\end{array}$ & $\begin{array}{l}\text { Programmes and } \\
\text { Projects }\end{array}$ & Detailed (economic) appraisal \\
\hline
\end{tabular}

Source: OECD (2015),

In developing countries, the key entry points (in relation to public planned adaptation) for advancing climate resilient development are likely to be aligned to the existing development planning process. This typically starts with a National Vision, i.e. the long-term aspiration for the country, which typically outlines the development goals to be achieved over the next fifteen to thirty years. Flowing from this 
is an operational plan to start the process of achieving these goals, which is advanced through the national planning process and national development plan, which usually have a future five year timespan. Examples include the medium-term plan, 5 year development plan or poverty reduction strategy. In turn, this national plan flows down to (or can be built up from) sector development plans/strategies or master plans, which provide the sectoral detail and align to the responsibilities of Government ministries and departments. Finally, these national (and sector) development plans feed down to down to regional, district or local plans. The possible entry points are summarised in Table 1.

Table 1: Possible entry points for mainstreaming in strategic planning policy in developing countries

\begin{tabular}{|c|c|}
\hline Planning level & Entry point \\
\hline $\begin{array}{l}\text { National government and } \\
\text { cross sector ministries }\end{array}$ & $\begin{array}{l}\text { - } \quad \text { National development vision (long-term) } \\
\text { - } \quad \text { Poverty reduction strategy } \\
\text { - } \quad \text { National development plan (e.g. } 5 \text { year ) } \\
\text { - National budget allocation process or review }\end{array}$ \\
\hline Sector ministries & $\begin{array}{l}\text { - Sector development plans } \\
\text { - Sector master plans } \\
\text { - Sector budgets }\end{array}$ \\
\hline Subnational authorities & $\begin{array}{l}\text { - Decentralisation plans } \\
\text { - District plans } \\
\text { - Subnational budgets }\end{array}$ \\
\hline
\end{tabular}

Source: UNDP/UNEP (2011),

Critically, this cascade also applies to the national budgeting process, and this allows the process to align to the allocation of finances (whether internally or externally) for adaptation implementation, as well as the existing government budget cycle of reporting, monitoring and evaluation.

\section{Mainstreaming Adaptation: an Example from Rwanda}

At the national level, strategic decisions are taken that create the enabling environment for publicand private-sector actors, as well as communities and individuals. As shown above, there is an opportunity to mainstream climate change into national and sector development planning. This study has reviewed case studies and the literature (academic and grey) to identify examples of mainstreaming and used this to develop some insights and potential lessons.

One of the earliest countries to mainstream climate change was Rwanda, and the country has one of the most advanced institutional landscapes in this area.

Following the publication of a Green Growth and Climate Resilience Strategy (the National Strategy for Climate Change and Low Carbon Development, RoR, 2011), there was a concerted effort to mainstream climate change in national and sector development planning. The Government of Rwanda introduced climate change (and environment) mainstreaming explicitly as one of seven cross-cutting issues in the national development plan (the Economic Development and Poverty Reduction Strategy 2013 - 2018, Republic of Rwanda, 2012). This integrated climate change risks into the national development plan, and this identified a number of policy areas where it was important to mainstream climate change into national development objectives and strategies.

The same cross-cutting objective of mainstreaming climate change and the environment was then included in the sector development planning process, and thus in the 5 year sector development plans that were being developed from the national strategy (e.g. for the Strategic Plan for the 
Transformation of Agriculture in Rwanda (PSTA), 2013-2018, RoR, 2013; and similarly for all sector development plans at the same time). At this level, strategic priorities were identified, and this included explicit plans for mainstreaming (e.g. mainstreaming soil conservation into agriculture). Specific mainstreaming activities were identified, along with early targets, indicators and budget allocations. Indeed, Rwanda has now included early environment and climate indicators in the budgeting process (issued as Annex 19 to the budget circular) so that there are incentives to start mainstreaming within public financial management.

Accompanying this, there is also provision for the additional financing of climate change mainstreaming activities in development plans through the Rwanda national environment and climate fund, FONERWA (GoR, 2012). This has a dedicated thematic window (for proposal applications from government ministries and departments) for 'Environment and Climate Change Mainstreaming'. This fund can therefore provide the incremental finance to fund the additional costs of mainstreaming within Government. A number of individual mainstreaming projects have already been financed under FONERWA, and there is an ongoing pilot on programme mainstreaming in the agriculture sector, summarised in Box 1.

This process has provided some useful lessons (FCFA, 2014). The adoption of climate change mainstreaming in Rwanda has been driven by the presence of a high level champion (the President), the incorporation in national level strategy (the low carbon, climate resilience strategy) and the recognition and inclusion of climate change as a key cross-cutting issue in national economic development planning (and subsequently sector plans). There has also been strong support from senior (powerful) Ministries that move beyond the environment ministry alone. Importantly, this has been accompanied by a pull factor, through the opportunity to obtain additional (climate) finance for the funding of incremental activities (for mainstreaming activities) through Rwanda's national climate and environment fund (FONERWA). There is also an emerging lever for implementation and monitoring and evaluation (M\&E) through the inclusion of mainstreaming indicators in the national budget circular. It is worth stressing that this institutional landscape has taken several years to build, and has been supported by external (international and local) technical assistance and capacity support. Indeed, a key finding has been that mainstreaming into sectors requires high levels of capacity building and support to progress the practical implementation: given pressure on time and resources in LDC Ministries, and mainstreaming is unlikely to happen without this. 


\section{Box 1: Mainstreaming climate change into agriculture sector development planning in Rwanda: tea and coffee resilience pilot (FCFA, 2015)}

While Rwanda has advanced mainstreaming in sector development plans, and there are strategic priorities identified, these remain at a general level. A key issue is therefore how to programme the implementation of mainstreaming. To advance this, a pilot mainstreaming initiative is ongoing in the Ministry of Agriculture and Animal Resources (MINAGRI). The pilot has identified a series of sequential steps for practical mainstreaming, shown in the figure below (adapted from Watkiss and Hunt, 2011). These steps reflect the shift in adaptation assessment and address the challenges that were identified in Watkiss (2015).

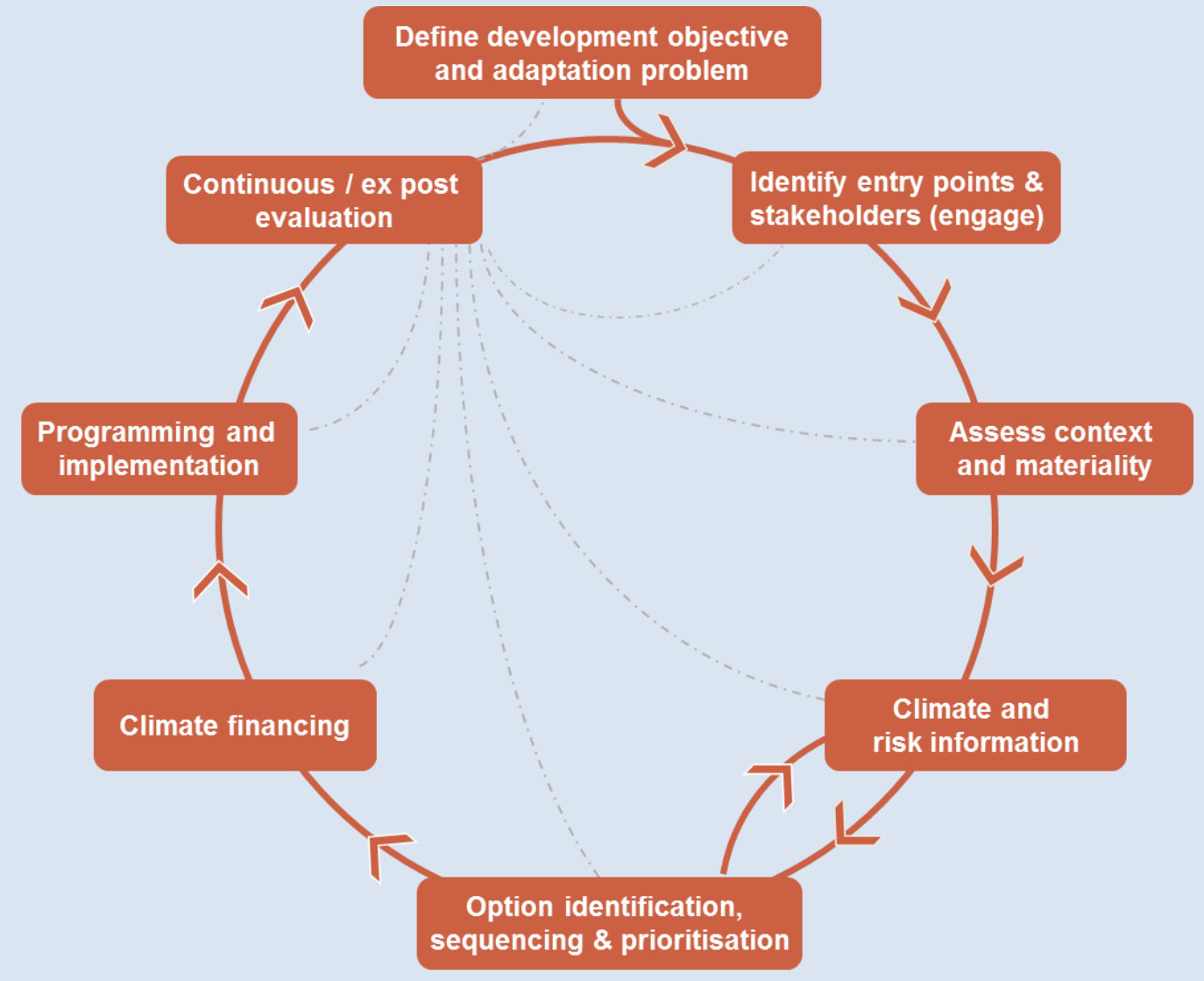

Interestingly, the key entry point identified for the initiative was the Agriculture Sector Investment Plan (ASIP2) (RoR, 2014) rather than the sector development plan, since this is the document that outlines specific activities, indicators and budget lines. An initial climate risk screening was undertaken for the ASIP2, identifying priority areas (climate risks and adaptation opportunities) across the 40 subprogrammatic activities in the plan, and one of the ten major areas identified was selected for a pilot initiative: for export (cash) crops, notably tea and coffee development, as these dominate existing agricultural exports, are a key part of the development strategy growth objectives and are climate sensitive. These are particularly interesting from the perspective of mainstreaming since the plan has an objective to double production, which will lock-in new land-use patterns for several decades to come. Following from this, the stakeholders involved in mainstreaming were identified, including the National Agricultural Export Development Board (NAEB) and the Rwanda Agriculture Board (RAB), that capture value chains and extension services, as well as local planning units and district planners, and of course farmers, co-operatives, NGOs and civil society, charitable trusts and foundations, and the private sector, including trade and sector associations. The subsequent analysis of climate information and identification and prioritisation of options is discussed in a later section. 


\section{Other Mainstreaming Examples}

Other examples are emerging, notably of mainstreaming into sub-sector plans and programmes. Huang and Wang (2014) - in a review supported by IDRC - identify one such example in China, in a project on mainstreaming climate change adaptation into irrigated agriculture (implemented by the World Bank and China and supported by the GEF-managed SCCF) focusing in the Huang- Huai-Hai River Basin. This is an area of major grain production but also periodic water shortages.

The project is helping to mainstream climate change adaptation measures, techniques, and activities into the national Comprehensive Agricultural Development (CAD) Program, China's largest national investment program in irrigated agriculture. The project initially identified and prioritized different adaptation measures, and then undertook pilots to demonstrate and implement the measures in selected demonstration areas. The process is being used to adjust and integrate appropriate adaptation measures into the implementation of the Third Irrigated Agriculture Intensification Loan Project (IAIL3) of China, to reduce vulnerability to climate change in the $3 \mathrm{H}$ Basin. Finally, the integration of adaptation into the national CAD program is being progressed, accompanied by institutional strengthening, capacity building, technical assistance, knowledge sharing, public awareness activities, and preparation of a national climate change adaptation plan for CAD by State Office of CAD, with the cooperation of Chinese Academy of Sciences (CAS), the National Development and Reform Commission (NDRC), China and Ministry of Finance (MOF), China.

One finding from the project is that increased local ability and institutional capacity is key for enhanced resilience (e.g., establishing water users associations and farmer associations) to react to changing circumstances. The project has ensured that communities have been better informed about climate threats, and has increased the level of information and encouraged its use in future investment choices.

It is stressed, however, that mainstreaming can involve different approaches. Some countries have developed separate national adaptation sector plans, but have sought to align these to the existing sector context. As an example, in Tanzania, following the national climate change strategy, individual ministries have been charged with developing sector specific incremental adaptation plans, that complement existing sector plans. The first plan has been undertaken with the Agriculture Climate Resilience Plan (URT, 2014).

The discussion above centres mainstreaming in strategic planning policy. However, there are also opportunities to mainstream at the project level. This again requires the identification of entry points.

In this context, existing safeguard mechanisms, such as environmental impact assessment (EIA), provide a possible entry-point for considering whether projects are vulnerable to climate change or could exacerbate climate risks elsewhere. Although originally designed to prevent negative impacts on the environment, the EIA process has the benefit of being a familiar and well-established part of the policy-making process in OECD countries (Agrawala et al., 2010). EIA does, however, only apply to those projects that are subject to environmental impact assessments, such as infrastructure construction, and it tends to be centred on environmental considerations, rather than broader mainstreaming concerns (indeed, it may require revision of the legal framework to include climate risks). More critically, the EIA process occurs relatively late in the project cycle. By the time it takes place, the project site and design is largely finalised, and the potential for option variation is much lower. For example, if there are major climate risks at the river basin level, these are more difficult to address at the individual project level. Indeed, it is possible that mainstreaming considerations are better incorporated in strategic environmental assessment (SEA), as this allows consideration of mainstreaming at a more strategic level early on, influencing siting for example, and consideration of sector strategy and the overall investment portfolio, including the subsequent set of projects. 
This has led to a shift to mainstream earlier within the process. This involves mainstreaming at the project concept stage and in early design as part of the main project cycle process. This can be seen in the recent introduction of climate risk screening and safeguard systems, which are being advanced by several of the International Finance Institutions and Multilateral Development Banks, as well as many Development Partners. For example, the African Development Bank (AfDB, 2011) has introduced a Climate Safeguard System (CSS) that includes a traffic light filter and scorecard to identify which projects may be vulnerable to climate risk early in the project cycle. Where potential risks or opportunities are identified, this flags the need for a more detailed analysis to consider the integration of climate aspects into design and implementation. These systems have particular relevance for developing countries as they introduce climate risk screening (and mainstreaming) into development in cases where concessional finance is involved, which includes many major projects.

It is also possible for individual countries to integrate similar screening into their own policy and project appraisal guidance. This is being advanced in some developed countries (OECD, 2015), such as the UK, with supplementary "Green Book" guidance published (HMT, 2009) to support policy makers in accounting for adaptation in economic policy appraisal. Some OECD countries have introduced allowances for flood protection standards (Wilby and Keenan, 2012) to update design standards. While such approaches could be introduced into developing countries, in many cases there is inadequate availability or implementation of policy and project appraisal guidance.

\section{Insights, Lessons and Future Research}

The analysis of the literature and case studies has provided some broad insights and potential lessons on mainstreaming and identified further policy research areas.

Mainstreaming does not occur in a vacuum and it is essential to understand and integrate adaptation within the existing policy and socio-institutional landscape. This is particularly important since adaptation will often be one of many policy objectives, and not necessarily the dominant one. It is therefore necessary to consider existing processes or guidance and appraisal documentation already in place. Such mainstreaming will be country, sector and even organisation specific, this cautions against the development of specific tools and approaches for generic use.

For mainstreaming to be effective, entry points must be identified, which align with the development planning or project cycle process and are aligned to an existing policy and institutional framework. The stage at the decision-making process when adaptation is mainstreamed is critical. Mainstreaming activities should come early enough in the process to influence the decision (as highlighted in the discussion of EIA above). There is also likely to be more success if interventions are targeted at key windows or "intervention opportunities" (Ballard, 2014) such as sector or local plan updates, infrastructure replacement and renovation, and even renewal and rebuilding post disaster. For example, ex post reconstruction following a disaster such Hurricane Katrina has resulted in an urban development patterns more cognizant of the possibility of such climate risks occurring in the future (O'Brien et al., 2012).

Pragmatism is essential and activities (and tools) need to fit with the resource, time, capacity and expertise available for policy or project analysts, otherwise there they will not get used. This may mean a focus on providing information and processes that are good enough, particularly given the potential complexity of climate change and uncertainty. There remains a major challenge over the availability and use of climate information in developing countries and this can act as a barrier to the incorporation of medium- to long-term climate assessment into core national development processes (Jones et al, 2015). 
One implication of mainstreaming is that it implies a much greater degree of resource and analysis, when compared to a science-first impact assessment (although the information from impact studies provides a valuable input into the mainstreaming process). This can be seen in examples that have applied mainstreaming concepts to national adaptation implementation (e.g. see OECD (2014) for examples in Ethiopia and Columbia). Mainstreaming also requires an understanding of the individual organisations, networks and processes that feed into relevant decisions, recognising these will differ between sectors and applications. It also requires information and data to allow an economic appraisal that aligns with standard policy practice, and accounts for the multiple drivers and objectives related to the policy background and context, including other cost and benefit categories.

In the case studies outlined above, some of the key lessons that emerged were that mainstreaming is helped by the presence of a high level champion, the involvement of strong Ministries (such as the Planning Commission and the Ministry of Finance), the availability of climate finance and critically, technical assistance and capacity building support.

In practical terms, the path from identifying potential entry points through to implementing mainstreaming processes is challenging. Achieving this requires the involvement of users and stakeholders, finding relevant champions, building partnerships and providing support networks. Such support networks will be particularly important as mainstreaming moves from a central unit (e.g. in the Ministry of Environment) out to other ministries. The complexity of decision support for mainstreaming needs to be considered against the capacity, time availability, capability and interest of sectors as it will inevitably involve switching from (or integrating with) other tasks. A critical factor in success has therefore been found to be capacity development, complemented by effective coordination and assistance, to augment the capacity in the sector ministries (e.g. agriculture, water) where activities will take place.

It is useful for decision-makers to also identify opportunities that can be created by implementing adaptation, rather than focusing only on the risks and amelioration actions. For example, establishing development zones connected to ports with efficient transport may incentivise infrastructure development in areas away from the coasts (Hallegatte, 2011).

Enhancing the understanding of the barriers or constraints to adaptation can help to recognise the disconnect between an idealised model of adaptation planning and the reality of how it plays out in practice (Cimato and Mullan, 2010; HMG, 2013) These lessons include the need to identify key barriers to effective adaptation (including market, policy, behavioural and governance failures), to build organisational adaptive capacity, and to introduce enabling actions that are likely to lead to more effective adaptation.

While there are challenges, there are advantages of mainstreaming. It is an effective way for implementation and can help address some of the challenges often identified with climate change adaptation. This is because mainstreaming aims for compatibility with existing systems, processes and guidance. Thus existing policy and project appraisal guidance has recommended approaches for baseline setting, and the analysis of non-market and qualitative benefits. Further, while discount rates and equity weights are potentially a contentious issue for climate change analysis, existing guidance and decisions on these aspects will already exist in the existing policy or project appraisal context. However, as more experience of adaptation mainstreaming develops, a recommendation is to reexamine existing systems, to see if they adequately incorporate the specific needs of adaptation. Mainstreaming is thus a continuing and iterative process, requiring the integration into existing policy and project cycles, but also a process of review, evaluation and learning.

Interestingly, recent mainstreaming plans have started to use iterative climate risk management approaches, as these can help address the challenge of uncertainty and help with prioritisation. These 
have a greater focus on capacity building and enabling steps (see next section). They also provide a stronger economic justification for longer-term action, which can often be missed in more traditional sector mainstreaming. As an example, the use of an iterative approach identified the long-term risks of climate change for the Ethiopian coffee industry, even though this had not been identified as a short-term vulnerability priority (FDRE, 2014). Iterative approaches also provide a framework for review, monitoring and evaluation, although these approaches do require more capacity to implement.

Finally, there is a need for more policy-orientated research on mainstreaming, advancing practical examples and ensuring that these processes are evaluated to provide learning, including through communities of practice and sharing of information and knowledge. In practical terms, the greatest need centres on technical assistance and capacity building. 


\section{II: The Appraisal of Capacity Building}

Key findings:

- The recent literature on adaptation has evolved from a focus primarily on technical options to a more comprehensive set of interventions that include capacity building, institutional strengthening, research and information, as well as non-technical (soft) options. These interventions are widely recommended as early low-regret priorities.

- Underpinning this shift is the recognition that adaptation can be seen as a process, which requires organisational capacity, and that there are important barriers to adaptation that need to be addressed to enable effective implementation.

- However, it is particularly challenging to appraise capacity building and institutional/organisational options in quantitative economic appraisal. We have investigated the analysis of these options, highlighting the type and timing of their costs and benefits.

- Many of these options can be quantified using value of information measures, for both early direct responses, as well as for informing future orientated decisions. There are also approaches that exist for assessing socio-institutional and organisational options, though most of these apply qualitative assessments.

- A review of the IDRC portfolio and the wider literature has found a number of good practice examples. These show examples of economic appraisal and demonstrate these options can produce high benefit to cost ratios. They also highlight important issues with assessment, notably the assumptions along the results chain.

- The analysis reveals important issues about the economic appraisal of these options, and also more widely on how to design effective capacity building and institutional support. These provide valuable lessons for the adaptation practice and further ex ante and ex post analysis of soft adaptation options is recommended, to help build the evidence base and to provide information to allow transferability.

With the move towards the practical implementation of adaptation, there is recognition that there are many capacity building and non-technical actions that are highly cost-effective and/or complement or enhance technical interventions. Indeed, these 'soft' options are a major part of recent adaptation plans and are recommended as an early adaptation priority in the literature. However, these nontechnical interventions are more difficult to assess using traditional economic assessment methods and this can mean they are excluded or are given less priority in policy or economic appraisal. This section of the analysis has investigated these types of interventions and explored their appraisal, drawing on underlying concepts and case study examples, to draw out insights and key lessons.

\section{Background}

As highlighted in Watkiss (2015), most of the earlier adaptation economics literature has focused on technical (engineering or 'hard') adaptation responses, such as flood defences, irrigation schemes, etc. This was primarily due to the available information on unit costs and benefit effectiveness for these options, which allowed quantitative analysis. However, more recent literature and the development of more practical adaptation strategies have widened beyond these technical options to include a much wider range of options. These comprise a suite of ('soft') options, which include capacity building, behavioural and non-technical options. 
The greater focus on these options has arisen for to a number of reasons. First, the consideration of a wider set of options more accurately reflects the typical diversity of interventions applied in policy and strategy, noting these usually include many non-technical options. It also reflects the greater awareness of adaptation as a (socio-institutional) process (IPCC, 2012) and the importance of adaptive capacity in delivering adaptation (and enhancing the delivery of technical options). There are also important barriers to adaptation, including market failures, policy failures, governance failures and behavioural barriers (Moser and Ekstrom. 2010; Cimato and Mullan, 2010) that make it more difficult to plan and implement actions, and/or lead to missed opportunities and higher costs, which need to be addressed to enable effective and efficient implementation.

The focus on these non-technical options is particularly apparent when looking at practical adaptation strategies in developing countries. A large number of options in national climate change strategies and emerging national adaptation plans - are non-technical in nature. They have a considerable focus on research, awareness raising and capacity building - as identified in a review of national documents in Bangladesh (MoEF, 2009), Rwanda (RoR, 2011) and Tanzania (URT, 2012: 2014). The importance of these capacity building and soft options has also emerged in many of the recent IDRC funded studies (discussed in Box 2).

\section{Box 2: Examples of IDRC funded studies on adaptive capacity and non-technical adaptation}

Madrigal-Ballestero and Naranjo (2013) investigated adaptive capacity, drought and the performance of community-based drinking water organizations (CBDWO) in Costa Rica, which are the most important providers of water in rural areas. The governance attributes and capacity of these organisations to deal with the threat of climate change is key (though there are often issues with their current performance, cost recovery, etc.).

The study explored the different factors and processes that have facilitated their ability to selforganize and to cope with actual and past periodical droughts using a sample of CBDWOs. Those that perform well against droughts tend to have a higher adaptive capacity. The study explored the underlying factors for this. While some factors for better performing organisations were technical (the type of water abstraction equipment), others included the degree of internal financing (from the community), the human capital of the water board (expertise, education, leadership) and the governance structure.

The study also looked at the various adaptation measures that CBDWOs had taken in the face of historic droughts, comparing hard, ecosystem based and soft options (the latter including behavioural options such as temporary bans or campaigns). The study found that CBDWOs tended to implement soft measures first, and if problems continued, they moved to metering (arguably a further soft option) and hard technical options. A key finding overall was that the implementation of adaptation measures was closely related to the enabling conditions that facilitate the high performance of CBDWO. Thus, adaptation depends on attributes of the resource system, the governance structure and the community of users, as well as their interactions. Another key finding related to the information needed for the design of options, with several cases where money was invested that did not lead to anticipated benefits. A key finding is that single uniform solutions are unlikely to offer the best adaptation solutions and a combination of building capacity, access to information for decisions, and governance and organisational aspects are critical.

Garcia Lopez and Tomás (2015) looked at individual and community-based adaptation to factors to drought in Mexican irrigation communities, exploring how governance, biophysical and social factors affected the ability to cope collectively and individually. It also explored the range of options 
adopted, with a finding that for effective collective responses, capacity building and institutional responses as well as technical ones, were important.

With respect to agriculture and climate finance, Huang and Wang (2014) identify a number of key priority areas, which includes research, science and technology development and capacity building. They identify priorities for improving national and local government capacity in developing and implementing their adaptive strategy and planning in both the long run and short run. This included investment to improve local community's ability of adapting to climate change and the extreme weather events in the short run; as well as investment to improve farmers' adaptation capacity to the extreme weather shocks or national disasters through training and/or establishing self-managed organizations. As an example of capacity building activities, they report on a recent agriculture project which improved agricultural water management capacity of irrigation management staff, water use associations, and farmers through participatory irrigation management and training programs.

A number of studies in the IDRC portfolio have also used econometric and economic studies to understand the determinants of adaptation - which helps to provide baseline information and identify barriers - and can thus help identify the non-technical areas that are important for future adaptation intervention. These include studies by Dehlavi et al (2015) in Pakistan, Thampanishvong (2015) in Thailand, and Chen et al. (2013) and Wang et al. (2014) in China.

\section{Typologies and Capacity Building}

There are a large number of types of non-technical adaptation, which cut across several themes and definitions in the literature. Earlier frameworks (Smit et al, 2001) classified adaptation into seven or so types (share the loss, bear the loss, modify the events, prevent, change use, change location, research, education and behavioural, further splitting prevention into structural/technological, legislative and regulatory, institutional, market-based and on-site options). While these are still sometimes used, a wide diversity of typologies has emerged over the last decade and there is no single categorisation that is universally used.

It is possible, however, to broadly differentiate (UKCIP, 2008) between those interventions which provide the enabling environment for adaptation (often referred to as building capacity), i.e. ensuring the information, institutional capacity and frameworks, organisational systems and resources, etc. are in place to adapt, and interventions that involve the actual delivery of adaptation directly. The latter are practical actions to either reduce vulnerability to climate risks, or to exploit positive opportunities, and may involve technical or non-technical options (e.g. coastal dikes, ecosystem based adaptation, insurance, changing locations, etc.).

The focus of this section is on the capacity building options, as these represent the challenge for adaptation appraisal. There are a plethora of concepts and definitions in this field, especially for the term 'adaptive capacity' which can lead to confusion: Box 3 presents and discusses common definitions.

However, when looking at capacity building from an economic perspective, it is less important to focus on typologies or categorisation, and instead to consider the types of interventions in relation to their costs, benefits, timing and phasing. This allows consideration of the subsequent economic costs and benefits in appraisal. 


\section{Box 3: Some notes on definitions}

\section{Building capacity}

Capacity building is a broad term (UKCIP, 2006: 2008) that involves:

-Gathering and sharing information (undertaking research, collecting and monitoring data, gathering and sharing information, and raising awareness through education and training initiatives);

-Creating a supportive institutional framework (changing standards, legislation, disseminating best practice guidance, and developing appropriate policies, plans and strategies);

-Creating supportive structures (building organisational systems, developing personnel, providing resources to deliver the adaptation actions).

\section{Adaptive capacity}

Adaptive capacity was defined (IPCC, 2007) as the ability of systems, institutions, humans, and other organisms to adjust to potential damage, to take advantage of opportunities, or to respond to consequences.

In this context, it was a key component of vulnerability, especially defined in technical terms as the outcome of exposure, sensitivity, impacts and adaptive capacity. In the recent $5^{\text {th }}$ AR (IPCC, 2014), adaptive capacity is defined as the ability of a system to adjust to climate change (including climate variability and extremes) to moderate potential damages, to take advantage of opportunities, or to cope with the consequences. However, the definition of vulnerability has shifted, defined as degree to which a system is susceptible to, and unable to cope with, adverse effects of climate change, including climate variability and extremes. More subtly, there has been a shift to consider the multiple definitions of vulnerability as the term has become more generically used.

Early economic studies advanced the concepts of adaptive capacity through concepts such as weakest link hypothesis (Tol and Yohe 2001: 2006) This built an indexing method for vulnerability based on the hypothesis that the adaptive capacity for any system facing external stresses could be explained by the weakest of eight underlying determinants (technology, resources, institutions, human capital, social capital, risk spreading, decision-maker ability, public perception). However, this approach is centred on an aggregated risks and high level assessment, rather than designing adaptation interventions (though the latter could also follow the identification of the key weakest link). A further macro-economic perspective to adaptive capacity was added through the consideration of key success factors (Vivid Economics, 2010: Bowen et al. 2012), which identified nine key success factors which are associated with fast and sustainable economic growth.

However, there are further definitions of adaptive capacity. The UK CCRA work (Ballard et al, 2013) defined adaptive capacity as the ability of a system to design or implement effective adaptation strategies to adjust to information about potential climate change (including climate variability and extremes), to moderate potential damages, to take advantage of opportunities, or to cope with the consequences. In this definition, 'adaptive capacity' is the capacity to take effective adaptation actions, i.e. the extent to which organisations are able to identify climate risks and make well-informed, long-term decisions that will make them more resilient to the impacts of climate change. This emphasises socio-institutional and organisational aspects, i.e. associated with the 'process of adaptation' at organisational and/or structural (sector) level. This work further differentiates adaptive capacity into two distinct components:

- Organisational adaptive capacity (OAC): a measure of the current ability of organisations within the sector to undertake effective adaptation actions in response to climate change.

- Structural adaptive capacity (SAC): a measure of the systemic factors currently at work within the sector that affect its ability to adapt to climate change; these include the sector's complexity, typical decision lifetimes, and the extent of activity providing potential opportunities for undertaking adaptation actions.

Underlying this is the assumption that capacity develops progressively, i.e. that organisations start off less effective, but grow capacity through learning, thus barriers that apply at early stages are different to those that apply when organisations improve. 
To do this, we use the conceptual frameworks on the phasing and timing of adaptation developed by Ranger et al., (2010); Watkiss and Hunt (2011) and Fankhauser et al. (2013). The focus is on early policy relevant decisions, i.e. those which are needed in the next decade to advance climate resilient development. As highlighted in Watkiss (2015), the framework includes three general types of interventions.

- Immediate actions that address the current adaptation deficit and also build resilience for the future. This involves early capacity-building and the introduction of low- and no-regret actions as these provide immediate economic benefits:

- The integration of adaptation into immediate decisions or activities with long life-times, such as infrastructure or planning. This requires different tools and methods to actions above, because of future climate change uncertainty. It involves a greater focus on climate risk screening, identification of the risks of lock-in, and the identification of flexibility or robustness.

- Early planning for the future impacts of climate change, taking account of uncertainty. This includes a focus on adaptive management, the value of information and future options/ learning, especially when decision life-times are long or future risks are very large or irreversible.

These three intervention areas are complementary and should be considered as part of a portfolio. There is, nonetheless, a set of capacity building options associated with each of the three areas, and these differ according to the types of intervention they involve and the type of benefit they provide. These are outlined in further detail below.

\section{Early low-regret actions}

The first category of interventions relate to short-term, low-regret adaptation that helps to address current climate variability and also build resilience to the future. This includes a set of technical interventions, but also a set of capacity building options. These act as an important precursor or enabler for successful adaptation, through information, institutional strengthening, awareness-raising, etc. Often these measures are highly synergistic to technical low-regret options above, creating the enabling environment or increasing the effectiveness of delivery. They can therefore be introduced as complementary packages of options with technical measures, e.g. as portfolios rather than single solutions (e.g. see Di Falco and Veronesi, 2012 for an example in agriculture, where a portfolio of improved seeds, soil and water conservation, better extension services and improved climate information, was found to be most effective in enhancing agricultural production in climate vulnerable areas of Ethiopia). However, these options have very different characteristics to the more outcome based options (above) and have benefits that are more difficult to assess quantitatively.

For options where information is generated to allow adaptation, or to provide information for early adaptation decisions, such as seasonal forecasting for agriculture, early warning systems for disaster risks, human disease monitoring, etc. it is possible to appraise costs and benefits quantitatively. The analysis of costs is relatively easy - though it is important to stress that while these options are low cost they are not cost free (e.g. with the capital costs associated with equipment and the resource costs of operation for enhanced forecasting). The analysis of benefits is more challenging, but in economic terms, investment can be justified - and benefits can be identified and quantified - through the estimation of quasi-option values, recognising that information has a value as it leads to different actions with learning, and allows higher benefits or lower costs as a result, hence the term often used is the value of information). It is possible to place an economic value on the benefits of this information.

To do this, the appraisal calculates the value or cost without information, and then compares this to value or cost if learning from this information takes place and action is taken. The difference between these is the economic value of information (Teisberg, 2002). There is a reasonable literature on the 
application of this approach with respect to climate services (Clements, 2013) and consideration of what this could mean for future climate change (Macauley, 2010). More details are given in the case study section below, which also provides some examples of the high benefit to cost ratios that result for these measures, reinforcing their potential as low-regret options. The challenge with this approach, however, is the difficulty in accurately calculating the level of use (in the results chain) - and the effectiveness of use - resulting from the uptake of information. This is easier in some cases, e.g. for early warning where there is good ex post data from previous events, but more challenging for generic interventions such as awareness raising, risk mapping or research.

The second low-regret area here relates to technical assistance and institutional strengthening. IDRC is supporting a number of good practice examples, with networks advancing capacity building and research on the economics of climate change. Examples are included in Box 4.

\section{Box 4: IDRC capacity building initiatives and economic studies}

The South Asian Network for Development and Environmental Economics (SANDEE) ${ }^{3}$ aims to strengthen the capacity of individuals and institutions to undertake research on the inter-linkages among economic development, poverty, and environmental change and to disseminate practical information that can be applied to development policies. It brings together South Asian researchers and institutes interested in the inter-connections between development, poverty and the environment. Its main goal is to build the professional skills required to enable South Asians to address local and global environmental concerns. SANDEE works in seven countries in South Asia Bangladesh, Bhutan, India, Maldives, Nepal, Pakistan and Sri Lanka. One focus area has been on the economics of climate change and the programme has funded many of projects cited in this document.

The Latin American and Caribbean Environmental Economics Program (LACEEP) ${ }^{4}$, aims to create capacity in the field of environmental economics among Latin American and Caribbean academic and non-research and policy-making institutions. It is a capacity building effort that provides research grants in environmental and resource economics to Latin American and Caribbean (LAC) researchers, as well as meetings, close advice and supervision, publication outlets, and opportunities for comparative research. Again there has been a focus has been on the economics of climate change and the programme has funded many of the projects cited elsewhere in this document.

One interesting aspect was incorporated in the Building Capacity to Adapt to Climate Change In Southeast Asia programme (Bui Dung The, 2014). The capacity impact of the project was assessed by comparing the level of knowledge and skills of researchers and LGU staff before and after their involvement in the project using data from a baseline survey at the start of the project and end-ofproject survey. This found the practical application of the project contributed significantly to research and training/ extension capacities (of the recipient institutions) through increased research skills of the researchers in the area of vulnerability assessment and economic analysis of adaptation options.

IDRC has also funded economic studies that explore the non-technical and institutional aspects of adaptation. Dehlavi et al (2015) looked at the impacts of climate on agriculture and adaptation in Pakistan. It looked at the returns on investment and considered on-farm adaptation options from existing adaptation including altered sowing/harvesting dates, shifted cropping patterns, changed levels and composition of inputs, increased soil conservation investment, and increased water

\footnotetext{
${ }^{3}$ SANDEE was launched in November 1999 and is hosted by the International Centre for Integrated Mountain Development (ICIMOD), Kathmandu, Nepal. SANDEE is supported by a number of donors and supporters in addition to IDRC http://www.sandeeonline.org/

${ }^{4}$ Supported by the Canadian International Development Research Center (IDRC) and the Inter-American

Development Bank (BID), http://www.laceep.org/
} 
conservation. It highlighted that the payoff from investment in Agricultural Extension Department training in these measures was high - as improving extension to farmers through farmer's associations was positively correlated with all adaptation strategies. In this case, benefits are high relative to the low cost of holding of farmer field schools, broadcasting of radio messages, curriculum printing, flyers and meetings and it considered this options more cost-effective than hard engineered options (such as irrigation systems, canals or reservoirs). The study also looked at some of the determinants of existing adaptation, finding for example, reliance on peer information, secure land tenure and membership of a farmer's association were positively correlated with adaptation. Interestingly there were some adaptation options which specific determinants, for example, household education and age were positively related to soil conservation adoption. The study also considered leverage points to encourage adoption and found it was important for planners to delve deeper into the institutional context of adaptation decisions.

Thampanishvong (2015) undertook analysis in the Chao Phraya River Basin in Thailand and assessed the determinants of farmer adaptation. Access to agricultural credit, the average rainfall during the rainy season, land tenure, number of members in the households and the socio-economic characteristics of household head were found to be the main drivers behind adaptation to severe flood. Results from the analysis indicate that access to credit, land ownership, vehicle ownership, household size and gender of household head influence farm households' adaptation to severe drought. One finding of the work is that lack of knowledge and information is one of the main barriers to adaptation, and thus information and training is a priority, and that access to markets might also help information dissemination.

Chen et al (2013) examined the influence of policies and social capital on farmers' decisions to adopt adaptation measures against drought in China. The study undertook a large-scale household and village survey and found that the majority\% of rural households have taken adaptive measures to protect crop production against drought, most of which were non-engineering measures (notably changing agricultural production inputs and adjusting seeding or harvesting dates). Using a multivariate regression analysis it found that government policy support against drought such as releasing early warning information and post-disaster services, technical assistance, financial and physical supports had significantly improved farmers' ability to adapt to drought - though also noted that only $5 \%$ of areas had received this support. Finally, the study found that having a higher level of social capital in a farm household significantly increases their adaptation capacity against drought, and that the ability to adapt to drought is also associated with the characteristics of households and local communities.

Wang et al (2015) assessed the effectiveness of adaptation policies for agriculture in the North China Plain. This included econometric analysis of the provision of early warning information and policy support on farmers' adaptive decisions regarding the planting of wheat, using village and farm survey with an econometric model of farmers' adaptation practices. The results showed that when faced with a more severe drought, farmers change their management practices to mitigate effects by adjusting seeding or harvesting dates and enhancing irrigation intensity. The provisions of early warning and prevention information and policy support (planned public policy) helps to facilitate farmers to make farm management adaptation. Information provision helps farmers might prevent potential losses by informing them about the possible duration and severity of the forecasted drought and by reminding them about measures that they could take to reduce losses. Prevention information (extension staff and technology researchers sent to the field) help to advise and encourage good practices. However, the effectiveness of these interventions differs by provision channel and type, e.g. depending on the media form used for information provision for example. The analysis helps to provide quantitative information on the benefits of non-technical adaptation (in terms of the take up of measures). The analysis shows that enhancing the adaptation capacity are particularly important for the effectiveness of climate adaption policies. 
The investment in organisational capacity is challenging to appraise. Despite the fact that development agencies recognise the importance of building the capacity of partner governments institutions, the quantitative estimation of the benefits is generally omitted from standard ex-ante appraisal, and often left to ex-post evaluation. The benefits from these capacity building activities are nevertheless significant.

There is some guidance (DFID, 2010) on how to design capacity building projects/programs, and this implicitly gives guidance on how to estimate benefits. This outlines that every intervention should be designed around a clear theory of change, and translated into a logframe able to link inputs to outputs to outcomes and impact. This requires that in the logframe, outcomes and indicators include "process" as well as "product" indicators to reflect desired changes in attitudes and behaviour as well as more tangible results. However, the guidance is not explicit about how benefits should be quantitatively assessed, though it implicitly prescribes to quantify and monetise (to the extent possible) the (intended) project outputs and intermediate outcomes described in the logframe, noting some will be estimated quantitatively, while others (such as soft skills) only qualitatively. The guidance also outlines how to measure value for money $(\mathrm{VfM})$ for capacity development/building projects by using the 3Es framework:

- Economy: To assess the cost of inputs, given the quality and quantity of the outputs they help deliver. A good measure of this is input unit costs.

- Efficiency: To assess how well a programme converts inputs into intended outputs.

- Effectiveness: To assess whether outputs are effectively delivering expected outcome.

However, it is challenging to measure the contribution of capacity development initiatives to results, not least because the results chain is long, and attribution difficult to quantify. Retrospectively, some projects have shown positive impacts and these are presented in the case study section. The ex-post literature contains important findings that can inform the design and the approach to appraising future capacity building programmes.

There are more general tools to help development practitioners design result-oriented capacity building projects, which may indirectly facilitate ex ante appraisal as well. The World Bank Institute (2011) published 'Steps for designing a results focused capacity development strategy', which provides guidance on how to measure capacity outcomes, including intermediate and soft outcomes. The latter include increased awareness, improved skills, improved teamwork, strengthened coalitions, or enhanced network. The Learning Network on Capacity Development (LenCD) provides guidance on How to Formulate Capacity Indicators and suggests that indicators for hard and soft capacities will be very different but both are worth considering. Hard capacities are generally easier to measure by the quantity and quality of outputs but may not be a good indicator of overall capacity. A focus only on indicators of hard or formal results will not, in the long run, be very helpful for providing information about the development of sustainable capacity. For this type of capacity applying SMART criteria can be helpful. Soft capacities are very important indicators of overall system capacity and the potential for sustainable change. Even if they cannot be measured, they can often be observed.

\section{Short-term decisions with a long life-time}

For the second category set of options, i.e. those that focus on immediate decisions with a long-life time $_{L}$ the focus is on what can be done now to address the potential impacts of climate change in the future. This involves a number of interventions.

The first is associated with climate sensitive infrastructure, e.g. hydro-plants or critical infrastructure, which have a long life time and will thus be potentially affected by climate change, either by changing trends or extremes, in the future. Addressing these risks can involve technical adaptation (e.g. 
changes in design) to address future risks. However there is also a critical role for information - as well as the capacity for using this information to make decisions - given the high future uncertainty involved in future climate change: examples might be the application in a climate risk screening or climate safeguard assessment. Where information is robust, it is also possible to change the regulatory environment - another form of capacity building - for example introducing higher design standards to cope with future changes. This includes design for infrastructure (e.g. for flood protection, or for hydro-power safety) as well as the use of information to enhance building codes. It can also include the use of information to design flexible (Hallegatte, 2009) or robust options (Lempert and Groves, 2010) rather than economically optimal ones, aligned to the decision support literature (see later section). Another example relates to forest management, where the choice of species and management need to be taken today, with a changing climate in mind, to still deliver benefits (e.g. timber revenues) in future decades.

The capacity building benefits in these cases are again associated with the value of information, though there is also a need for organisation to have the expertise to use this in making these decisions and hence a need for institutional strengthening and technical capacity to enable this. However, it is more difficult to appraise the value of information in this case because the benefits occur in the future, and are dependent on the baseline conditions and benefits derived, on which there is uncertainty. This makes it more difficult to ascertain the baseline counterfactual and to assess the benefits that adaptation will deliver. The difficulty of making these measurements is then further exacerbated by the need to apply discount regimes, i.e. the need to discount future benefits that arise from the use of the information. In the developing country context, this is a particularly important issue, due to high discount rates used (or the high internal rate of return needed on investment).

A second application area for short-term decisions with a long life-time relates to planning decisions, particularly those that lock in patterns of development for long time periods, e.g. urban planning, coastal development, rural land-use change. In this case, the adaptation intervention can relate to siting (location), for example, using urban or land-use planning to avoid areas that are at possible increased future risk and reducing lock-in to future risks (Ranger et al, 2014). This can include planning design or legislation to create set-back zones in low lying coastal areas at risk of future sealevel rise. Again the main benefits are from investment in information and capacity to improve nearterm decisions to address future climate change. This is usually advanced through the provision of information on current and future risks (e.g. risk mapping) and risk screening. As an example, risk mapping has the potential to provide information to reduce future property damage (e.g. from flooding associated with climate change). It also helps people to make decisions on where to live and what prevention measures to take (World Bank, 2010). It also needs to include the investment in capacity and communication/ dissemination of this information, to ensure it reaches those end-users who can derive benefits from it, or the changes in regulations or legislation to enforce (e.g. for setback zones) all of which involves costs. As for the case above, the appraisal of the benefits is more complicated than it may first appear, due to the need to consider future (discounted) benefits in the results chain, for what are often probabilistic events which involve uncertainty. Furthermore, there are often hidden costs, for example, precluding areas of land development (e.g. with set-back zones or land-use constraints) because of future (uncertain) risks can involve opportunity costs from the foregone use of the land, and will involve enforcement costs: there is a need to consider these upfront costs against discounted future benefits. For these reasons, the attractiveness of these options can vary quite significantly, e.g. with studies reporting some cases where the benefits do not outweigh the costs (ECONADPT, 2015).

It is stressed that in most cases, the generation of information is low-cost. The critical issue arises from the subsequent use of that information, and the benefits in the results chain and the comparison against the costs of the actions introduced. For this reason, there is a large variation in the potential value of information according to how effectively it is used, e.g. with respect to the consideration of 
uncertainty, the economic analysis of what subsequent costs can be justified by future benefits, etc. and it is possible for information to lead to maladaptation as well. This highlights that alongside the value of information, there is a need for organisational capacity to be able to use it effectively and efficient, which itself has a cost.

\section{Preparing for the future under uncertainty}

The final set of actions relates to longer-term (future-orientated) interventions, i.e. early action/ decisions for addressing future climate challenges. The key difference to the category above is that the decision takes place in the future, thus it implements early action today to allow learning and enhance decisions in the future (Ranger and Reeder, 2011; Watkiss and Hunt, 2011) especially for climate change where there is large future uncertainty.

This is particularly important where information gathering or research takes time or where decision time-scale is long: in both cases early steps are warranted now to start planning for the future and enhance the effectiveness of future actions. For example, the Thames Estuary 2100 project (EA, 2009: 2011) used iterative adaptive management to develop a tidal flood risk management plan for London, developing a short-, medium- and long-term programme. The project included a monitoring and evaluation strategy (recommending investing in enhanced sea level monitoring today) with established decision points, such that if the monitoring reveals SLR is happening more quickly (or slowly), options can be brought forward (or put back). This is particularly important as planned major capital investments outlined in the plan can actually take decades to design, plan, consult, get planning consent, finance and build. There are also examples that are perhaps more relevant to LDCs. It can take 20 years to develop, test, plant and mature new varieties of cash crops such as coffee (FRDE, 2015) that are suited for shifting agro-climatic regimes under climate change: there is insufficient to wait for the temperature change to occur before adopting this strategy thus an early priority is to begin the initial research and development immediately, and to draw up plans on how to respond to levels of future risk. These plans can then be implemented (earlier) if higher warming is observed. A further example where such an approach is warranted is where there is the potential for major (or even irreversible) long-term risks (with high uncertainty).

In all these cases, the key capacity building option therefore relates to immediate activities that generate information for future decisions or actions, and again the concept of the value of information is relevant. When major capital investment is involved, this can be assessed through real options analysis - discussed in the final section. In the adaptation context, this allows for the analysis of flexibility, based on learning and acting on future information. Real options analysis (ROA) (Watkiss et al, 2014) allows consideration of whether it makes more sense to wait for new information and so potentially avoid future negative outcomes, rather than investing immediately, . It therefore allows analysis of whether the benefits of the new information outweigh the costs, i.e. with respect to delaying implementation. The approach also allows consideration of flexible options that can act on the information and change direction in the future, e.g. with infrastructure that can be easily upgraded in the future, noting this has a cost penalty) compared to options that do not have such flexibility. Finally, it can be used to consider whether it makes economic sense to start the initial stages or a project, such as feasibility or initial investments, to keep the option open for potential future investment. In all cases, this can inform a decision-maker who faces uncertain conditions about what might be gained by obtaining new information, as compared to deterministic approach. ROA can be used to estimate the value of information/quasi-option values, but as highlighted (Watkiss et al, 2014) it is most applicable to major, capital investment projects since it is time and resource intensive to apply. Nevertheless, the concepts of the value of information from ROA can be applied to consider the benefits from more general in early actions that provide improved future decisions, noting that the early investments themselves are usually low-cost. 


\section{Case studies}

There is a considerable literature and case studies on the value of information associated with climate and hydrological information, in terms of addressing current climate variability (i.e. early low regret options). These consider the effect of additional information and the additional value added for the users of that information. There have been many studies that have quantified the costs and benefits of investing in meteorological equipment/climate services, particularly focused on long-term and seasonal forecasts. A review of this literature (Clements, 2013, updated in DFID, 2015) has identified around 30 such studies, primarily for agriculture, where benefits have been quantified and valued, and then compared to costs. These typically show high benefit to cost ratios (in the range 2:1 up to $36: 1$ ).

Benefits arise from the use of information to enhance agricultural production or avoid losses (e.g. crop selection and the timing of planting and harvesting, as well as water management), and are compared to the costs associated with investment in meteorological stations, system operation and information provision ${ }^{5}$. There is also similar potential for the use of climate information in Malaria Early Warning Systems (MEWS) and from investments in enhanced hydrological information through the value of information provided and the subsequent improvements in water resource management and reduced water security risks, the latter showing high benefit to cost ratios (World Bank, 2012).

The benefits vary strongly with the assumptions about use of information and uptake along the chain ${ }^{6}$, i.e. how effective and valuable the weather information will be, on the assumptions about the uptake of information (e.g. the proportion of farmers) and on the assumption that forecasts are reliable.

There are also a reasonable number of studies (ECONADAPT, 2015) that undertake appraisal of information (from meteorological or hydro-meteorological information) for use in early warning systems (EWS) for evacuation or preparation in advance of tropical storms or floods. The benefits arise from the anticipation and preparation for extreme events and the reduction in damage costs to assets and fatalities and injuries avoided. Again, these reported high benefit to cost ratios (e.g. ECONADPT, 2015; World Bank, 2011). The World Bank (2013) reports values of 5:1 though with a wide range, and much higher benefit-cost rations for some highly vulnerable LDCs. Benefits vary according to the effectiveness assumed, whether non-market impacts are valued, and on fully capturing the categories of activities (and costs) associated with effective systems. The benefits of these systems generally increase under climate change, because of the higher storm surges with sea-level rise, the potential changes in storm intensity and frequency and because of increasing flood risks in many areas.

There are few studies of the value of information associated with short-term decisions for future benefits (immediate decisions with a long-life time). There are, however, assessments of the

\footnotetext{
${ }^{5}$ It is worth noting that generating forecasts is complex and requires the collection and sharing of data in a systematic and timely manner, telecommunication systems that allow exchange of information, numerical weather prediction models, which simulates the physics of the atmosphere, computational facilities for processing data and models to generate forecasts at different spatial and time scales and resolutions (World Bank, 2010). It also requires the communication and dissemination channels to get forecasts to end users and qualified staff. This implies costs may be significant when introducing from low baseline levels.

${ }^{6}$ Recent analysis has identified the steps in this weather chain as forecast accuracy, tailored information, access, comprehension, ability to respond, effectiveness of response, redistribution (leaks) of initial benefit and highlights the issues of service use and information decay along the chain (Perrels et al, 2013): this requires 'cost-loss' (CL) analysis, which focuses on the effects of changes in forecast accuracy in an otherwise fully informed world, combined with weather service chain analysis (WSCA).
} 
application for early action/ decisions for addressing future climate challenges, with the use of real options analysis (see above discussion).

The value of information can be used to justify investment in early research, on the basis of learning. Alternative approaches can also be used, for example using information from typical returns on investment in research in the relevant sector or area. An example of such an approach is frequently used in agricultural research. For example, studies of previous agricultural knowledge $\&$ information systems (World Bank, 2000) found that returns averaged 88 percent on investments in research and 79 percent on extension. Rates of return were similar across all research categories except for natural resources research, where lower rates of return were mainly due to longer production cycles.

Similarly, the literature on the costs and benefits of technical assistance and institutional strengthening is scare. There are some assessments of forums/institutional strengthening and awareness-raising in the context of disaster risk management and emergency/contingency and response plans. An IDRC-funded study by Cartwright et al. (2013) compared these types of institutional options against hard options in Durban in the context of adaptation. The analysis used an adjusted form of CBA, whereby benefits were calculated in relation to the number of people impacted and the extent of the welfare benefits imparted by the respective adaptation efforts, because of concerns about the use of standard cost-benefit analysis and its weighting on monetary metrics, as well as high levels of economic informality and inequality. The adjusted CBA method was applied to a large number (16) of different options for four possible future scenarios representing different combinations of socio-economic and climate change to derive benefit-cost ratios over three different time frames $(0-4$ years, $0-50$ years and $0-100$ years).

The study found that four adaptation interventions emerged as economically efficient across all futures and time frames, namely: the creation of a cross-sectoral disaster management forum (with $B C R$ ranging from 62 in the best case scenario to 46 in the worst case scenario); sea level rise preparedness and early warning system (BCR ranging from 66 to 19); the creation of climate change capacity within the municipality's water unit (25 to 14); and the creation of municipality-wide adaptation capacity in government, civil society and communities (27 to 16). These were much higher than more conventional technical options (asset protection, dams), and even ecosystem based adaptation. It also emerged that the marginal cost curves evaluated under the future scenarios that assumed low levels of socio-institutional capacity yielded less than half the economic efficiency of those scenarios where institutional capacity was assumed to be strong, pointing to the importance of having strong governance for the benefits of climate change adaptation to materialize.

There are some limitations to this approach. The analysis of benefits is more subjective and possibly sensitive to contextual factors, framing effects, task complexity issues etc. (because it is driven by people's belief that capacity building activities will be very effective and result in benefits for a high number of people). Nonetheless, it does provide a quantified appraisal of socio-institutional options and indeed, these emerged as the most efficient interventions across all futures and time frames.

There are other studies that look at the benefits of institutional strengthening for improved watershed management and integrated water resource management (Mechler, 2005: De Bruin et al, 2009), both in relation to reducing current climate risks, as well as enhancing future resilience to climate change,

Ex post analysis of technical assistance projects has also demonstrated that the cost of improving governance, increasing the capacity for sector oversight, and strengthening government institutions significantly improves the use, distribution, and management of benefit streams. Successful implementation of technical assistance projects has resulted in substantially increased investment, improved government oversight over the sector, and greater accountability of revenue streams generated by the sector. 
Some commentators (e.g., MacMahon, 1997) have advocated that the appraisal of such aspects is important and should be considered more quantitatively.

It is possible to undertake such analysis by considering the benefits of technical assistance using evidence from previous studies (and their ex post findings). An example of such an approach is given in the World Bank (2012) analysis of technical assistance for an urban local government strengthening programme in Tanzania.

Other appraisals have sought to quantify benefits of technical assistance. An example in Mozambique for an Agricultural Sector Public Expenditure Program Project (World Bank, 1999) did this by estimating the agricultural GDP growth rate that would be necessary to justify the investment (the switching value). This highlighted that only a small increase (less than 1\%) from the programme would justify it on cost-benefit terms. The appraisal then went further and also monetized some of the outputs in the sectors, which were considered directly linked to the technical assistance. An analysis was carried out for the various components, based on returns: (i) to crop production, (ii) to livestock production; (iii) to forestry and wildlife, and (iv) to irrigation investment. As an example, for crop and livestock production, the net on-farm returns from improved crop productivity were set against the incremental costs of the Government extension service, research service and regulatory functions. The financial rate of return on crop production activities was about 29 percent.

A similar approach has been used in some recent DFID climate institutional programmes, in the economic appraisal of the business case, such as in Tanzania (DFID, 2015). This recognized that the evidence base for the direct economic returns of institutional capacity building is relatively weak. The study therefore examined the potential for the programme to influence and improve the effectiveness of existing climate-relevant flows, exploring how much the programme would have to improve effectiveness by to justify spend. In this case, the result was that the programme would only need to deliver a $0.2 \%$ improvement to justify the investment, delivered by increasing outcomes per $£$ spent in climate relevant sectors through better programme design, coordination and delivery. The analysis also considered the potential for the institutional programme to increase the volume of finance flows, due to enhanced institutional arrangements, again using a similar approach to find the increase on current flows that would need to be delivered to justify the investment. Finally, the programme applied a similar approach to look at the inclusion of a monitoring, evaluation and learning (MEL) component, again looking at the increase in effectiveness from the investment. There are some obvious limitations with these approaches, as estimating the increase in effectiveness is challenging. However, the use of switching value approaches provides a way to benchmark the realistic increase in programme performance and compare this to costs.

Guidance on undertaking impact assessment of capacity building and training was also produced by the Australian Centre for International Agricultural Research (ACIAR, 2007) along with case studies. Their framework outlines three broad approaches to estimating the share of the benefits attributable to a capacity-building activity, depending on whether the capacity built is considered: i) neither necessary nor sufficient, but led to improved outcomes ii) necessary but not sufficient, or iii) sufficient in isolation to have resulted in significant benefits. The study provides two country-based studies (India and Vietnam), which used ex post evaluation to extract the technical assistance portion responsible for the overall benefits. For the Indian projects, a benefit-cost-ration of 28:1 was found. For the Vietnam project, the ratio was 13:1. These are both very favourable.

More commonly, there is no economic assessment of technical assistance undertaken, on the basis that these activities do not lend themselves to net present value or rate of return calculation. Many appraisals therefore consider projects on the basis of the cost-effective achievement of development objectives. For example, these may highlight (e.g. World Bank, 2013) that similar technical assistance 
projects executed in other countries have demonstrated that the cost of improving governance, increasing the capacity for sector oversight, and strengthening government institutions significantly improves the use, distribution, and management of benefit streams. As a consequence, successful implementation of similar technical assistance projects has resulted in substantially increased investment, improved government oversight over the sector, and greater accountability of revenue streams generated by the sector.

There is a wider literature on capacity building and institutional options from the existing development literature (see Box 5), which provides useful lessons on how to design effective programmes.

\section{Box 5: Lessons on building capacity}

The World Bank's evaluation of its capacity building work in Africa concluded that capacity development, which is country-owned, results-oriented and evidence-based, should be treated as a core objective.

OPM (2012) conducted a multi-donor evaluation of public sector governance. It found that donors continue to under-estimate the importance of organisational capacity, with a focus on where the action appears to be, rather than the overall framework of government. They target specific operational units rather than line ministries. The evaluation found some successes, but, in general, donors and partner governments paid insufficient attention to organisational capacity as a means of development sustainability.

The European Centre for Development Policy Management research on Capacity, Change and Performance reports that external actors can facilitate but not drive domestic change processes - by providing access to new resources, ideas or connections. Further, analysis by the centre has not identified a single best strategy to support capacity development, but emphasises the need to develop a good understanding of the local context, have open discussions with partners, consider the political and intangible aspects of capacity, and unleash domestic potential and leadership, for example through learning and adaptation.

There are some studies that have recently reported on success factors for building capacity for adaptation (Ballard, 2013a: 2013b: Frontier, 2013). These conclude activities are strengthened when:

- There are well understood risks, particularly in organisations with in-house capability to prepare and respond (noting the links with mainstreaming) and/or already operational planning for similar risks.

- There are few indirect risks or interdependencies with other sectors.

- Support networks exist for individuals and smaller organisations, particularly where they have fewer resources and cannot plan for the long term, e.g. for farmers.

- There is strong organisational structure and leadership and coordination between organisations in sectors, including good partnerships and collaboration.

- There is a stable, supportive and transparent policy environment so organisations may plan and take effective action, and agents of change (champions) and strong leadership.

- Planning and processes are flexible and embedded into decision-making.

- There has been previous experience of a climate change impacts.

\section{Insights, Lessons and Future Research}

With the trend towards more practical adaptation, there is a greater focus on capacity building, institutional strengthening, research and information, as well as non-technical (soft) options. 
These options are widely recommended as immediate low-regret priorities but are more challenging to conduct economic appraisal on

The analysis above shows that some of these options can be quantified using value of information approaches, for informing both short-term direct responses and longer-term future orientated decisions, although these time-scales involve different aspects. There are methods for assessing socioinstitutional and organisational options, such as considering ex post examples of similar projects, costeffectiveness analysis and using switching values to justify the investment. However, current practice generally focuses on qualitative assessments.

A review of the IDRC portfolio and the wider literature has, however, found a number of good practice examples. These show that appraisal is possible, and that soft options often produce high benefit to cost ratios, though these are dependent on a number of assumptions

Finally, it is clear that this topic warrants future analysis and more detailed evaluation, especially as these capacity building and institutional strengthening programmes are one of the main activities in the IDRC portfolio and are being considered in national to local level adaptation programmes. There have been initiatives to undertake evaluation and collate examples of the ex post impacts of capacity building for use in ex ante appraisal. An example is ACIAR (2007) on productivity, including in the agricultural sector. Further research and evaluation work would be useful to generate a targeted set of ex post assessments for adaptation, focused on relevant capacity building and institutional strengthening/technical assistance interventions for use in future orientated appraisal. This also would provide valuable information for monitoring and learning, consistent with the emerging focus on iterative adaptive management in adaptation practice. More broadly, there is a literature on capacity building and institutional options - from the existing development literature as well as emerging findings for adaptation- that provide useful lessons on how to design effective programmes -These are highly relevant for similar activities in the adaptation domain and a review of the lessons for adaptation would be useful. 


\section{III: Distributional effects}

Key findings:

- Climate change has strong distributional effects, disproportionately impacting on poor and vulnerable groups. A key issue is whether these differences are taken into account when assessing climate risks and designing adaptation interventions.

- A review of the evidence base on climate change impacts and adaptation reveals that this issue has been qualitatively recognised, however, there has been little quantitative consideration, and to date distributional issues have not been integrated into adaptation plans and appraisal.

- This mirrors the picture in the development literature: approaches (such as distributional weights) to address such issues do exist, but they are rarely used in economic appraisal: instead common practice is to consider the distributional effects of policies or projects qualitatively.

- A review of the IDRC portfolio and other studies has found a number of good practice examples, where qualitative approaches have been used. These studies provide some key lessons and identify areas for future research. Further consideration of these distributional issues - in both risk assessment and adaptation design - is highlighted as a priority for future adaptation assessment and policy applications.

The IPCC 5th Assessment Report (2014) highlights that people who are socially, economically, culturally, politically, institutionally, or otherwise marginalized are especially vulnerable to climate change. It also outlines that more severe (relative) impacts of climate change are likely to arise in developing countries, and these will fall on the poorest within these countries.

A number of questions follow from these differentiated patterns. First, there is a question of whether the impacts on different groups (distributional analysis) are considered when assessing climate risks, and then subsequently when designing adaptation programmes and interventions. Second, in terms of economic appraisal, there is the question of whether distributional consequences are factored into the appraisal (formally or informally) to produce more equitable allocations of available funds or to give greater weight to more progressive interventions. These issues are explored in this section.

\section{Background and evidence base}

The effects of climate change will differ across regions and countries (IPCC, 2014), with the most negative impacts occurring in developing countries, and especially for people living in poverty within these countries. Indeed, IPCC (2014) concludes that climate-change impacts will exacerbate poverty in most developing countries and create new poverty pockets in countries, leading to increasing inequality.

The fact that risks are unevenly distributed and are generally greater for disadvantaged people and communities leads to the question of whether - and how - this should be taken into account when assessing risks and when designing adaptation policy and interventions. It also highlights the question of whether climate finance should be preferentially directed to those who are most affected by climate change. Distributional impacts, i.e. when the distribution of the costs or benefits of interventions across groups in society differs, can arise due to differences in income, age, ethnicity, location, disability, gender, etc. They occur for a number of reasons, which are important in considering responses. The poor are more vulnerable because their exposure is often higher (Skoufias et al. 2011), for example, due to geographical location. They are also affected because their adaptive capacity is 
generally lower, including economic wellbeing and stability, as well as natural resource dependence, demographic structure and dependency ratio (Vincent, 2007). The sensitivity to potential impacts may be higher in vulnerable groups, such as for children or the elderly). Furthermore, even when impacts are more evenly distributed across society, they often have larger consequences for the poor, because the poor spend a greater proportion of their income on certain expenditure items such as food and are thus more affected from price changes.

There are many studies that show that distributional effects are an important factor in climate change, indeed this finding has emerged strongly from the surveyed case studies (discussed in Box 6). These provide empirical evidence for the presence of strong distributional consequences for climate change.

\section{Box 6: Studies of the distributional effects of climate variability and climate change}

There is a large literature that highlights the distributional effects of climate change. A selection of studies are summarised below, primarily drawing on projects funded within the IDRC portfolio.

Jayachandran (2006) investigated the impact of weather anomalies on labour in India, and found that productivity shocks cause larger changes in wages when workers are poorer, less able to migrate, and more credit-constrained because of workers' inelastic labour supply.

Borja-Vega C. and de la Fuente A. (2013) investigated a municipality vulnerability index due to climate change and concluded that larger producers are more resilient and locate in less vulnerable municipalities in Mexico, whereas small and subsistence producers are more likely to live in highly vulnerable municipalities.

Rios et al (2014) looked at the potential behaviour of inhabitants facing climate change in Mexico, and found that the scarcity of common use resources (water), created higher levels of inequality. They found that under scenarios in which there was less water available, extractions became more unequal. The study highlighted that the design of public policies should consider inequality e.g. with scenarios of scarcity of common use resources.

Adhikari (2003) looked at the distributional issues of community-based resource management in Nepal and examined the contribution of community forestry to household-level income with particular emphasis on group heterogeneity and equity in benefit distribution. He concluded poorer households were currently benefiting less in absolute terms from community forestry; further aggravating the inequity in distribution of benefits.

Chen et al (2013) examined the influence of policies and social capital on farmers' decisions to adopt adaptation measures against drought. They found that having a higher level of social capital, e.g. support networks in the community, for a farm household significantly increased their adaptation capacity against drought. They therefore recommended that adaptation policy should pay particular attention to farming communities, and farmers within a community who have a low level of social capital.

There is therefore a strong argument for considering these effects in a distributional analysis, where possible explicitly assessing and quantifying these, and including in such an analysis to allow consideration in the design and prioritisation of interventions.

However, while the literature provides a strong basis for the need to consider distributional issues, this has not fed through to most mainstream climate risk and adaptation assessments in developing countries. The recent evidence base collated by the ECONADAPT study (ECONADAPT, 2015) identified over 500 studies on the economics of adaptation, including over 50 national level studies. The 
consideration of distributional effects throughout this literature was scarce: while some studies provided qualitative discussion on the potential effects of climate change on different groups, there was a lack of distributional analysis to investigate this and provide empirical evidence. Additionally, no examples were found where adaptation policies had explicitly taken account of distributional factors in prioritisation of adaptation actions.

This omission is surprising though it is possible it is a side-effect of the contentious issues of this topic in the mitigation domain, with regard to the aggregation of global impacts. In the mitigation context, the aggregation of impacts on different groups over space (and time) - and the differentiate economic valuation estimates used for similar impacts in different regions - is a major source of disagreement, as it involves ethical and moral assumptions (see Anthoff et al, 2007: Anthoff et al, 2009).

These inter- and intra-generational aggregation issues, however, should be much less important for near-term national and local scale adaptation. Furthermore, their omission is likely to actually exacerbate the distributional consequences of adaptation responses. Standard cost-benefit analyses does not capture inequality and impacts on the most vulnerable explicitly, and implicitly it often gives greater focus to more valuable assets and groups (Cartwright et al., 2013). Similarly, in aggregate economic estimates of impacts, there is an underestimation of the impact of climate change on subsistence or near subsistence activities (as these are not part of the formal economy), thus the impacts of climate change on livelihoods may be severe without having much impact on GDP. As an example, a study of climate change impacts on Namibia (Reid et al., 2008) concluded that, even in the worst-case scenario studied, overall GDP might fall by only 5 per cent or so - yet half of the population would lose their livelihoods destroyed and would have to find new means of survival. It also may give lower weight to benefits that accrue to poorer communities. For example there is an issue of how costs and benefits be weighted where one community or stakeholder benefits and another suffers, as an example when an industrial user's access to scarce water means a loss of access for small-scale farming communities (Berger and Chambwera, 2010).

\section{Analysis of Distributional Effects}

Having recognised the existence of asymmetric impacts, there is the question of whether and how to take account of these. A number of different approaches are possible.

- Distributional issues can be taken into account in economic appraisal (in cost-benefit analysis) by using equity (distributional) weights to adjust present values. However, as highlighted above, very few adaptation studies apply equity weights and this reflects the practice in development economics more generally, where the use of distributional weights is rare.

- Assessment (quantitatively or qualitatively) of how the impacts of climate change - and the costs and benefits of an adaptation responses - are spread across different socio-economic groups. This can then be used to consider the ranking of adaptation interventions so that they take account of (or at least consider) these distributional consequences.

Distributional considerations can be incorporated into cost-benefit analysis of public polies using socalled "distributional weights", whereby monetary equivalents are adjusted by weighting factors reflecting individuals' incomes (with lower-income individuals tending to get larger weights), or other welfare-relevant attributes such as health, life expectancy, or environmental quality (Adler, 2013).

Distributional weights aim to capture differences in the social marginal utility of income, recognising that a dollar impact to a poor person is not the same as to a rich person (due to the diminishing marginal utility of additional consumption, Watkiss, 2011): following from this, an extra dollar spent on adaptation will give more benefit to a person who is poorer than to one that is richer. 
Through distributional weights, the decision maker operationalizes his/her ethical preferences. Underlying this, distributional weights reflect the inequality aversion of the policy maker (Adler, 2013), and as the decision maker's aversion becomes larger, he/she gives more and more priority to welfare changes affecting those at lower utility levels.

The use of distributional weights thus affects how policies and projects are ranked and selected. By using weights the policy maker increases the weight given to welfare benefits occurring in the poorest groups, and by doing so he/she influences NPVs and other indicators used in CBA for selecting policy options. However, in practice, a major challenge is the availability of the information needed to apply distributional weights, especially in developing countries, and this is exacerbated when it comes to the subsequent analysis of how adaptation might affect different groups.

One development partner that has advanced some guidance on the use of distributional weights is the UK Department for International Development (DFID). DFID is - in theory - required to use distributional weights in its appraisals, reflecting the guidance from the treasury in the green book $\left(\right.$ HMT, 2011) ${ }^{7}$. However, it is acknowledged that the cost of acquiring information to apply distributional weights has to be assessed against the importance of the proposal and the likely scale of the impact of distributional analysis (see the DFID Economic Appraisal training module). Examples of the use of distributional weights in social transfer programmes are included in the case studies presented below.

The use of distributional weights in CBA has, however, been subject to criticism and as a consequence it is not a widespread practice. This is because they are often seen as an arbitrary and are based on a non-transparent decision of the decision maker, and because they might have adverse incentive effects (Adler, 2013). In the climate change context, alternative metrics may be required to capture welfare effects of climate policy more fully (Hunt and Ferguson, 2015) - however, while measurement of capabilities or well-being might be more useful than income, the practical implementation of such approaches remains under-developed and would have analytical and data challenges.

As a result, most development partners use alternative qualitative approaches to accounting for equity issues in their appraisals. However, there is a large variation in practice.

The Asian Development Bank (ADB) use distributional analysis and shadow prices as a way to convert financial appraisal into economic appraisals, and extend economic CBA to a social CBA that explicitly incorporates equity concerns ${ }^{8}$. The approach requires identifying, first, winners and losers from the financial transactions of the project and, second, winners and losers from the divergences between economic and financial values. The ADB Guidelines (ADB, 1997) also requires decision makers to undergo a poverty impact analysis, which builds on the distribution (or stakeholder) analysis, although it requires additional data.

The World Bank also has a more nuanced approach. In 1998, The World Bank published the Handbook on Economic Analysis of Investment Operations (Belli et al., 1998), which clarified and simplified the existing Bank's guidelines for economic analysis by eliminating the inclusion of different public and private sector income (fiscal) weights and distributional (poverty) weights in the calculation of expected rate of return; however, the guidelines require appraisers to clearly indicate the fiscal and distributional implications of the project. Furthermore, the World Bank's Environmental and Social

\footnotetext{
${ }^{7}$ The Green Book provides guidance on what weights to apply, stating that 'Broadly, the empirical evidence suggests that as income is doubled, the marginal value of consumption to individuals is halved [...]. In other words, an extra $£ 1$ of consumption received by someone earning $£ 10,000$ a year will be worth twice as much as when it is paid to a person earning $£ 20,000$ per annum' (see HMT 1993, page 94).

${ }^{8}$ The World Bank follows the methodology first developed in United Nations Industrial Development Organization (UNIDO, 1972) and modified in minor ways in UNIDO (1978).
} 
Impact Assessment (EIA and SIA) guidelines require analysts to identify whether a project will impact on vulnerable groups and indigenous people.

\section{Case Studies}

The study has evaluated a number of examples on the use of distributional analysis.

DFID has been using distributional weights in the appraisal of social protection schemes (DFID, 2013). As an example, in the DFID Rwanda social protection project, benefits received through the scheme were weighted relative to average consumption. On average, the consumption of the scheme's beneficiaries (before transfers) was around RwF 80,000 compared to RwF 137,000 for the population as a whole. On average, therefore, benefits were weighted at $137,000 / 80,000$ or 1.7. Transfers to households with above-average consumption were less than 1 . The value of weighted benefits therefore reflected the extent to which the programme was targeted effectively towards the poor; the poorer the beneficiary, the higher the weight, while transfers to the rich would be weighted below the value of the transfer. The weighting applied to all monetary benefits received by households (transfer values, returns from investments, and increased productivity due to nutritional impacts), but not the value of DALYs averted (as is consistent with WHO's approach) since all changes in the risk of fatality was valued equally.

An example of distributional analysis by ADB is given by Gajewski et al. (2004), who looked at three case studies in the conflict and post-conflict areas of Tajikistan, India, and the Philippines, to appraise how road rehabilitation projects would impact on the poor and very-poor. The authors used field data, including tailored small surveys, focus group discussions, and key informant interviews to estimate the degree to which the poor used roads and would directly benefit from their rehabilitation (e.g. as users, labourers, or through government transfers). They also made policy recommendations involving further institutional changes that could increase the share of benefits that will accrue to the poor.

In relation to IDRC funded projects, Roy (2007) appraised the economic costs of arsenic-related health problems and welfare gains from arsenic-free water. The author estimated the welfare gains for different income groups (poor, middle-income, and rich groups), and found that for the high income group welfare gains were statistically insignificant. The author concluded that this was because the higher income group was already less adversely affected by arsenic and would gain relatively little from arsenic removal. The IDRC funded study of Cartright et al (2013) - discussed above - also undertook a CBA in which benefits where calculated using a different approach to address economic informality and inequality concerns, using a people-centered metric, comprised of the product of the number of people benefiting from a particular intervention, the frequency with which those people benefited, and the extent of the benefit that was imparted to people.

There are other IDRC funded studies where distributional aspects have been taken into account.

A study looking at river Mayur at Khulna, Bangladesh (Dasgupta et al. 2015) undertook a cost-benefit analysis to assess a programme to revive the river (primarily for water supply, but also for wider ecosystem service benefits). The analysis is notable in that it advanced economic valuation for assessing the value of ecosystem services. It also considered a range of specific options within the programme, and for each of these it undertook qualitative and quantitative analysis to map the gains and losses from a proposed change in the ecosystem provisioning services to different groups.

A further IDRC funded study, Dehlavi et al (2015), looked at the impacts of climate on agriculture and adaptation in Pakistan. It considered a number of on-farm options, as well as leverage points to encourage adoption. It considered the determinants of adaptation behaviour to help prioritisation of these options. This provided some interesting findings on the distributional design of adaptation, for 
example, finding that there was no need to prioritise wealthy farmers (as measured by total land holdings) as they were already advanced in their use of adaptation measures for all crops.

IDRC also funded a series of studies by IIED (Lunduka et al, 2012) which advanced stakeholder costbenefit analysis, with pilots in five countries focusing on the water sector. The study method recognises that one of the main challenges of CBA is accommodating for the wide-ranging impacts of climate change on diverse individuals and groups, and that this is a particularly acute issue for the water sector, as resources extend across geographical and political boundaries, and adaptation often involves decisions and actions by multiple stakeholders with differing shares in the costs and benefits of initiatives. The economic approach developed therefore took account of the distributional aspects of adaptation using stakeholder-focused CBA. As well as providing economic analysis, the process was found to facilitate dialogue among stakeholders to seek solutions that address diverse needs and interests. The five country studies were:

- Bolivia (Latin America). This study looked at how stakeholders identify and prioritise adaptation strategies for domestic and industrial water supplies in urban areas, and assessed the monetary and non-monetary costs and benefits of the prioritised options.

- Morocco (African Sahel). The monetary and non-monetary costs and benefits to different stakeholders generated by changing from surface to drip irrigation systems were examined.

- Malawi (sub-Saharan Africa). This study focused on an autonomous adaptation strategy to internalise the costs and benefits of irrigation, and its effects on the fishery and bird sectors in a wetland catchment.

- Bangladesh (lowland southern Asia). The main issue here was how different stakeholders weight the cost and benefits of adaptation strategies, and how this weighting can be used to adjust the costs and benefits of each option.

- Nepal (highland southern Asia). This study looked at the way that stakeholders identify and prioritise adaptation strategies, and how their willingness to pay for them is influenced by the perceived costs and benefits of each strategy.

\begin{abstract}
. A key challenge in all of the case studies was integrating the costs and benefits for different stakeholders into a common framework to inform decision-making. This issue was addressed at various stages of the project, starting with a compound cost-benefit assessment that covered all stakeholders. This was followed by separating the costs and benefits for different stakeholders in order to inform the process within which they debated which options to pursue. The studies also found that the design and targeting of interventions or the enabling environment could be used to address distributional concerns, for example, targeting smallholder farmers to address access to finance, providing them with greater parity with large-scale farmers who do not face such constraints. The studies highlighted a more general issue in relation to the difference in distributional effects of planned public adaptation and government funding for projects versus instruments or mechanisms that incentivised the private sector, noting that when the latter is introduced, it needs to be appropriately targeted to maximise the benefits for all stakeholders.
\end{abstract}

\title{
Insights, Lessons and Future Research
}

While there are clearly important distributional effects from the impacts of climate change, to date these have not been systematically or rigorously assessed in most studies. As a consequence, the consideration of how to design adaptation interventions to address distributional concerns remains an underdeveloped area, despite its importance.

This is a concern. It is also an issue if - as many believe - international funding for adaptation should address the needs of those most affected by climate change. As a consequence distributional and equity issues need to be given greater prominence than they currently receive in current costbenefit frameworks (Berger and Chambwera, 2010) 
What is clear, from this review of current practice, is that the answer to this problem is unlikely to be through the use of distributional weights. This is because these involve a number of assumptions that undermine their use, and perhaps more relevance, they are not used routinely in development economic appraisal currently. It is therefore unlikely that adaptation will be the trigger to change organisational practice. A lack of data to allow quantitative analysis reinforces this conclusion.

As a consequence, it is more likely that these effects will be integrated using the current practice of qualitative analysis of distributional consequence of policies. This involves quantitative or qualitative analysis on how the impacts of climate change are spread across different socio-economic groups and, from this, the consideration of distributional effects for adaptation policy. For the latter, there are two related issues. The first concerns the targeting of adaptation. In cases where the differentiated impacts of climate risks have been identified, it should be possible to allocate the share of adaptation resources and responses appropriately, i.e. reflecting the fact that the poorest are projected to have a disproportionate impact of climate change. In cases where there is a more even distribution of impacts, or an absence of information on the distributional effects, then a weighting can still be applied (e.g. through a criteria ranking as part of a multi-criteria analysis) to target the most vulnerable/poorest groups. The second issue relates to the types and design of adaptation interventions. It is possible to consider different interventions in relation to their effectiveness across different groups to ensure that interventions are designed so that they favour vulnerable groups or at least do not actively disadvantage them.

Finally, in the developing country context there is a greater need to consider the distributional issues associated with both climate risk and adaptation assessment and this area is highlighted as a priority for future research to help pilot and advance such analysis. 


\section{V: Prioritisation and Light-Touch Uncertainty Analysis in Appraisal}

\section{Key findings:}

- With the greater focus on adaptation implementation - and the emerging climate finance to fund this - there is an increasing need to prioritise adaptation.

- There are two key stages where prioritisation is relevant: at the scoping phase and in detailed appraisal. While there currently exist routine methods for both of these, there are a number of additional challenges for adaptation.

- In the scoping phase, a key issue concerns the short-listing of options: this can be advanced by considering the timing and phasing of adaptation. Our analysis provides some case studies on such approaches.

- In the detailed appraisal phase, a key challenge is the high uncertainty involved. The most common techniques used in economic appraisal (such as expected value analysis) have limitations in addressing this, and a suite of new decision support tools have emerged that advance decision-making under uncertainty. However, these approaches are complex to use and have high capacity and resource demands, which are a barrier to their application.

- A key priority is to develop more pragmatic (light-touch) versions of these new decisions-support methods, which can capture core concepts of decision making under uncertainty while maintaining a degree of economic rigour. Our analysis provides case studies of these approaches.

Future work to advance and demonstrate these light-touch approaches is needed, especially if these can be integrated into the more policy orientated and climate finance proposals, especially for developing countries.

The prioritisation of adaptation involves major challenges, not least over the timing of climate change and the high uncertainty involved, which affect the potential choices and resulting benefits. Furthermore many existing scientific assessments do not provide the necessary information for practical policy orientated adaptation, i.e. for early implementation and prioritisation of options over the next 5 to 10 years.

This section investigates the question of prioritisation, recognising the role for economic assessment for this - and more specifically for climate finance applications. It considers the prioritisation of adaptation at different phases of developing adaptation policies, plans and projects, drawing on case studies to provide examples and draw lessons.

\section{Background}

Public policy and project appraisal involves a systematic decision-making process: understanding the problem; identification of options; appraisal of options (and implementation approach); planning and implementation; and finally monitoring and evaluation. This approach is often formalised through guidance on impact assessment or economic appraisal and evaluation, for both policy and project decisions. 
Earlier impact-assessment driven studies of adaptation did not consider this broader appraisal framework, and instead largely considered adaptation external to established processes. However, in recent years, there has been a shift towards adaptation assessment more closely aligned to the policy implementation cycle above, e.g. such as in the UN PROVIA initiative?

In terms of the standard policy or project cycle, there are two points where decision support tools are particularly important;

i) for shortlisting options and

ii) for prioritising the shortlisted options.

In the adaptation context, there is an emerging community of practice and useful examples for both of these steps, outlined below.

\section{Scoping and early prioritisation}

The process of identifying a short-list of options (e.g. scoping or feasibility) includes, for instance, identifying focus areas for a national plan or strategy, options for mainstreaming climate change into a development sector plan or identifying a broad list of options for an individual policy or project. The aim of these processes is to filter options down to a manageable short-list of priorities, which can then be appraised in greater detail.

There are standard methods for shortlisting options, which may take the form of scoping economic analysis, simple attribute analysis and ranking, or stakeholder consultation and expert elicitation. These are common to most policy or project cycles, and can thus be included within an adaptation planning or mainstreaming perspective. In the national context, most adaptation examples have been part of national or sector action planning and this move continues with national adaptation plans (LCD EG, 2012).

Previous studies have considered a large number of methods for early scoping, including economic and other criteria to short-list options. A key innovation of more recent approaches is that they include criteria that are of direct relevance to adaptation. For example, some studies have included criteria to reflect the urgency of the option, while others have included criteria to assess if options have 'no'- or 'low-regret' characteristics, , which are included alongside the standard consideration of costs and benefits. One practical example is the national Routeplanner exercise in the Netherlands (De Bruin et al., 2009).

In the climate adaptation context, more recent scoping assessments have started to use iterative climate risk management to help with the scoping and initial prioritisation phase. This has been captured in the literature through frameworks or principles: examples include Ranger et al., (2010); Watkiss and Hunt (2011); Fankhauser et al. (2013). This trend was reported in the IPCC 5th Assessment Report, where the term 'iterative climate risk management' was used (IPCC, 2014).

The aim is to help filter the wide range of potential options by considering the phasing and timing of adaptation (DFID, 2015). This allows analysis of the order (and timing) of options, i.e. which to

\footnotetext{
${ }^{9}$ Programme of Research on Climate Change Vulnerability, Impacts and Adaptation (PROVIA, http://unep.org/provia/HOME/tabid/55173/Default.aspx) is a global initiative which aims to provide direction and coherence at the international level for research on vulnerability, impacts and adaptation. Provia was supported by the Mediation Project (Methodology for Effective Decision-making on Impacts and AdaptaTION, http://mediation-project.eu/). This project provided scientific and technical information about climate change impacts, vulnerability and adaptation options, including the adaptation learning cycle, methods, decision support and information (Hinkel and Bisaro, 2013).
} 
implement first, as well as which options may be needed early on to help with future climate change in the future (see also the types of interventions and decisions outlined in section II). These include i) immediate actions that address the current adaptation deficit and also build resilience for the future, ii) integration of adaptation into immediate decisions or activities with long life-times, iii) early planning for the future impacts of climate change, noting uncertainty.

Introducing an economic perspective to the application of iterative management in these early screening stages is especially useful, as it helps in the justification for identifying focus areas and filtering down the options. As an illustration, it could identify enhanced disaster risk management to address the current adaptation deficit (a large existing economic cost, and thus a low-regret priority) as well as to highlight opportunities for including "resilience" into infrastructure development or planning processes, where there are long life-times, and advancing research and monitoring to help future longer-term decisions. Examples are given in the case study section below.

Precursor work on the economic impacts of climate change can help inform this step. IDRC has funded a large number of econometric studies in this area (including Ricardian, hedonic and production function approaches) that examine the relationships between climate (historically) and agriculture (looking at the effects on land values, production, prices, etc.. These provide useful information on current risks that extremely important as the starting point for low-regret adaptation. Examples include Dehlavi et al (2015) in Pakistan, Escobar, Torres and Cabrera in Mexico, Thampanishvong (2015) in Thailand, Ahmad et al (2014a: 2014b) and Javed et al (2014) in Pakistan, Huang et al. (2015) and Wang et al. (2013: 2015) in China. Alongside this there have been a further suite of national level studies on the economics of adaptation. These were identified in Watkiss (2015).

\section{Detailed Appraisal and Decision Making Under Uncertainty}

Following the prioritisation of shortlisted options, there is a more detailed phase where shortlisted options are assessed and appraised. This phase is traditionally assisted by the use of a variety of decision support methods and tools, such as cost-benefit analysis. However, applying these tools to adaptation involves a number of challenges. The most important of these challenges relates to the high uncertainty involved with projections for future climate change.

As a consequence, alongside traditional decision support approaches (cost-benefit analysis, CBA; costeffectiveness analysis CEA and multi-criteria analysis, MCA) there are new approaches that are being developed and applied for adaptation that better allow for consideration of uncertainty. These are summarised in Figure 2. 
Figure 2: Decision support tools for adaptation economic appraisal

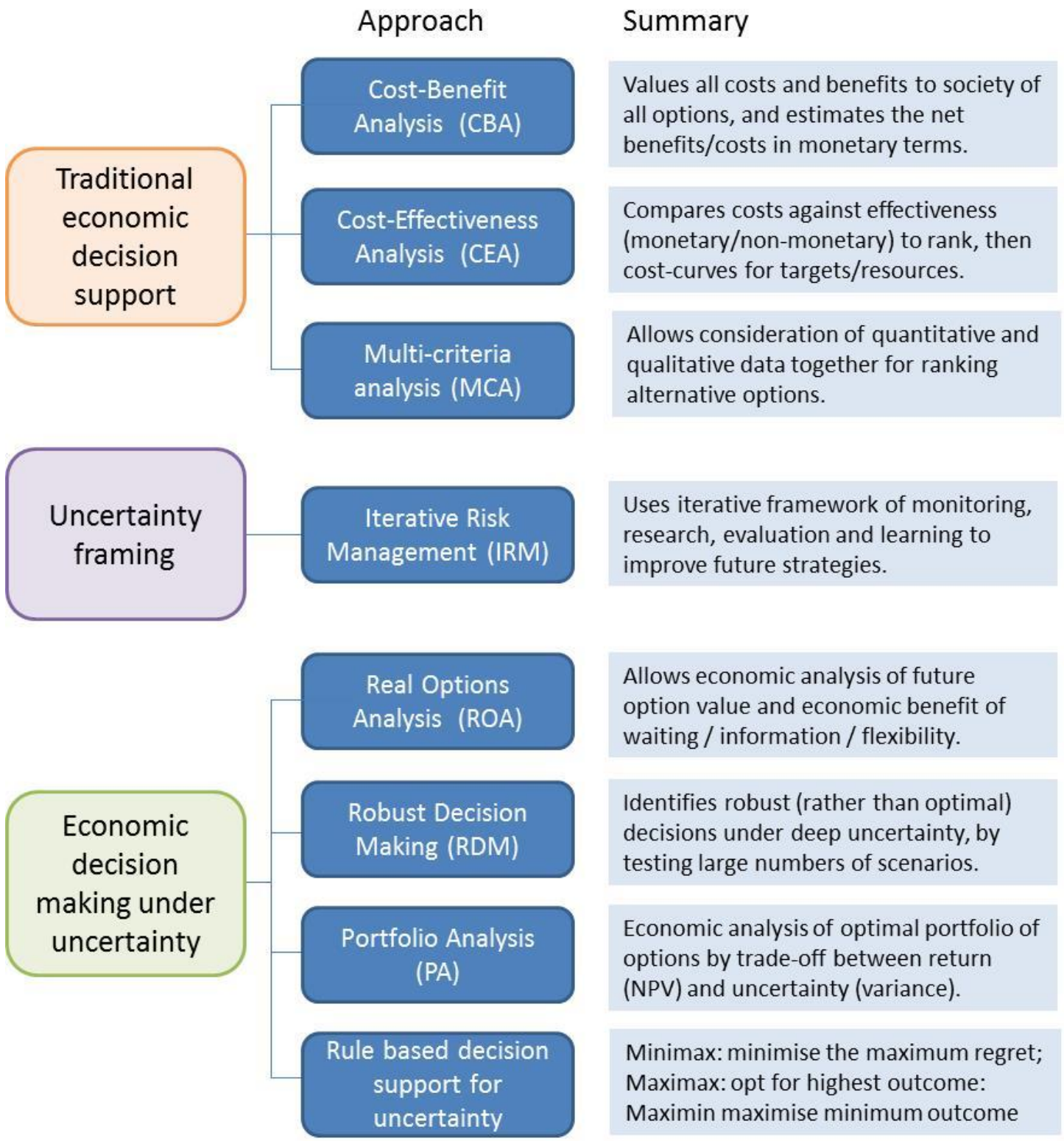

\section{Decision support tools for adaptation economic appraisal}

Source: Watkiss (2015), Watkiss et al. (2014).

The traditional methods at the top of the figure are often suitable for short-term low-regret adaptation options. Indeed, IDRC has funded a number of projects that have undertaken such analysis, summarised in Box 7. 


\section{Box 7: Examples of IDRC funded adaptation cost-benefit studies}

A series of IDRC funded cost-benefit studies were funded, under the Building Capacity to Adapt to Climate Change in Southeast Asia Programme. As well as advancing estimates of the damage costs of climate variability, these also undertook cost-benefit analysis of adaptation options to address current challenges. Bui Dung The and Bui Duc Tinh (2014) applied cost-benefit analysis to examine the economic feasibility of upgrading the current flood control system in the An Xuan tributary basin in Quang Dien district, Thua Thien Hue province, Vietnam to cope with current floods. The costs and benefits of the project were identified, the latter using different valuation methods (a market-based method and the contingent valuation method (CVM)). The analysis looked at upgrading the entire dike in the An Xuan tributary.

The CBA results show that such adaptation is economically feasible, although the estimated values of its benefits using the two valuation methods were not the same, with the CVM giving the larger value. While the analysis focused on current risks, the fact that floods are projected to increase with future climate change provides a greater imperative for early action. Nyda, Hoeurn and Naret (2013) undertook a cost benefit analysis of adaptation options to address (current) drought in Cambodia, looking at rehabilitating an inactive water reservoir. The study looked at the cost of drought at the household level, and found a positive benefit:cost ratio for the project. Finally, Bayani-Arias et al (2013) examined adaptation options for three lakeshore municipalities in the Sta. Cruz River Watershed in the Province of Laguna, Philippines. The study adopted a phased approach to prioritise a short-list of adaptation options. This ranked the initial long list of adaptation options using criteria from stakeholders (effectiveness, multiple goals/benefits, social acceptability/legitimacy, practicality/low barriers, scalability/replicability, equity and urgency) and that checked that the options were feasible/legal. It then undertook a cost-benefit analysis of a technology-based early warning system, using willingness to pay estimates, finding that the project produced large social net benefits, with a high Benefit Cost Ratio (BCR). It also conducted a case study comparing the (risk-based) costeffectiveness of three options suitable for flooding: relocation, evacuation center, and building modification. The results suggested that building modification was the most cost-effective option, whilst relocation was the least.

IDRC also funded work on adaptation cost-benefit analysis in Durban (Cartright et al, 2013, see section II) and a study by IIED (Lunduka et al, 2012, see section III). The latter developed and applied stakeholder cost-benefit analysis. This helps address a particular issue in developing countries, which is that analysis is hampered by a lack of scientific data: this approach allows available data be supplemented with local knowledge, which can be obtained from different stakeholders, including local communities.

However, the use of decision making under uncertainty is needed to tackle longer-term climate change (DFID, 2014), i.e. for more future orientated adaptation. Potentially suitable methods include real options analysis, robust decision making, portfolio analysis as well as iterative risk management and rule-based criteria.

As highlighted in Watkiss (2015), while there is an increasing evidence base of such applications, these are predominantly stand-alone assessments, rather than mainstreaming assessments. There are also no hard or fast rules on when to use a specific approach and none of them provides a single 'best' method for all adaptation appraisal. They all have strengths and weaknesses, although certain tools lend themselves more to specific contexts, sectors or problems. 
However, a key finding is that these new methods - at least when applied formally -are resourceintensive and technically complex. This is likely to constrain their formal application to large investment decisions or major risks (i.e. large-scale adaptation infrastructure projects). Importantly - in the context of climate resilient development - this is also likely to constrain their application in developing countries, where challenges of time and resource needs will be compounded by data and capacity constraints. They also take time to apply, which means they will often not fit within the available time for policy analysis, especially in a development context.

A critical question highlighted in the review was on whether the concepts of these uncertainty approaches could be used in "light-touch" approaches, i.e. that capture their conceptual aspects, while maintaining a degree of economic rigour, both at policy and project level. This would allow a wider application in qualitative or semi-quantitative analysis.

\section{Light-touch concepts and case studies}

At a simple conceptual level, many of these new approaches can be simplified for use in more 'lighttouch' applications. This could include the broad use of decision tree structures from real options analysis, the concepts of robustness testing from robust decision making, the shift towards portfolios of options from portfolio analysis, and the focus on evaluation and learning from iterative risk assessment for long-term strategies. The latter technique does lend itself more easily to a light-touch approach, because it allows differing degrees of analytical detail to be used within a broad conceptual framework.

Historically, applications have been more centred in the OECD - but there are applications emerging for developing countries. One example at the national scale was in the context of the climate resilience plan for agriculture in Ethiopia (FRDE, 2014 - also reported in OECD, 2014).

Additionality, a recent application for Rwanda has also been undertaken in the development of an agriculture climate mainstreaming programme, starting with a pilot on tea and coffee sector (see also section I). An outline of some of the options identified from this case is summarised in Box 8.

Guidance on the application of these light-touch approaches - for developing countries - has been produced by DFID (DFID, 2015) as part of an early value for money adaptation initiative (www.vfmadaptation.com).

\section{Box 8: Example of a light-touch approach for early prioritisation in Rwanda}

In the Rwanda case study on mainstreaming climate adaptation into the tea and coffee sector, a set of early interventions was identified through iterative management - using the DFID guidance. This identified options across the three sets of types of adaptation priorities (FCFA, 2015).

i) Early low-regret options. This included opportunities for improving the productivity and quality of tea and coffee today in Rwanda, by helping farmers cope with current climate variability and the nearterm impacts of climate change, especially targeting these interventions based on risk. As an example, for coffee an option was the introduction of shade trees or inter-cropping, as these provide cooler temperatures that increase quality as well as co-benefits including additional income streams. A subsequent cost-benefit analysis was undertaken, looking at different sub-options, building on existing pilot work in the country.

ii) Climate-smart planning. The second area focused on near-term decisions on land-use planning that have a long life-time notably on the tea expansion areas. This identified geographical and climate information needed to consider the siting of new industrial areas for tea, especially which surrounding 
areas should be encouraged to enter into small-holder production, using elevation and risk mapping data to ensure that low lying areas are avoided. This is particularly important to advance now, as decisions are being made over the next few years that will last decades, thus there is a critical window of opportunity, and a risk of lock-in.. More detailed analysis of exactly how far upwards (towards cooler climates) is being undertaken, using some portfolio analysis.

iii) Early planning for the future. This final category is looking at the future risks, where there is the opportunity for learning, and thus a value in starting initiatives today. One example identified was for pests and diseases, which could start to significantly affect coffee under a changing climate in the future. However, there is a lack of information on which areas of Rwanda might be affected by changing pests and disease, and a lack of monitoring information to enable effective responses. Investing in information in this area would provide the first steps in understanding changing patterns, and in developing pest management strategies. The project therefore identified a coffee pest monitoring programme and future risk mapping exercise, as well as a planning assessment to start thinking about how to develop future scale-up and control (as well as information and dissemination) based around possible economic thresholds.

The other three techniques for addressing uncertainty in appraisal - real options analysis, robust decision making and portfolio analysis - are more challenging to develop into light-touch approaches, because they are more prescriptive and have greater core data requirements and are more complex, thus they are more typically used in project level assessments.

Nonetheless, there has been some progress advancing these types of light-touch applications (Ranger et al., 2013).

For real options analysis, one particularly useful aspect that has broader application is the use of decision-tree analysis. This analysis traces out possible outcomes and decision points associated with a dynamic decision context. While the formal approach assigns probabilities and estimates expected values, it is possible to use these decision trees to think through a problem qualitatively. Indeed, the existing HMT (2009) supplementary guidance gives one such example (although it includes indicative NPVs as well) examining the choice of whether to build a standard sea wall or one that can be upgraded in the future.

Decision trees can be used to think through and apply iterative risk management, in that they can help to identify where there is the potential for information to help inform future decisions. They can also be used to help think through at what point there might be an alternative option that is more flexible. Finally, decision trees can be used to identify possible activities that could be started immediately that would help keep future options open (e.g. early research or monitoring). Indeed, this was largely the approach used in the Rwanda example in the box above.

For robust decision-making, it is possible to simplify the analysis by limiting the uncertainty to specific parts of the problem, for example, by looking at climate model uncertainty, to at least capture some of the important elements of uncertainty and to think through options that are more robust, even if this does not capture the full uncertainty and richness of a Robust Decision Making (RDM) application. As an example, Dessai and Hulme (2007) focused on the uncertainty from climate models - rather than running a full RDM assessment. A simple matric approach is presented by Ranger (2013), which considers options against uncertainty based on expert opinion, participatory decision making (e.g. ranking options through workshops) or on sensitivity analyses on the CBA, CEA or MCA (or a combination) - as well as providing an option to use rule-based criteria to filter out options. 
Lempert and Kalra (2011) distinguish between a "full" and a "heuristic" RDM approach. For the latter, computer simulation are not undertaken, but the analytical steps are the same (i.e. identify performance indicators, identify possible options, consider vulnerability and coping capacity, assess the strategies, identify if potential strategies and assess trade-offs).

However, Daron (2016) argues this is still too demanding for the practical application for developing countries. Drawing on insights from a case study of adaptation of coastal infrastructure to changing environmental risks in South Africa, the author highlights that there are major barriers to RDM in developing countries given the realities of decision making processes, the need to combine quantitative data with qualitative understanding and competing environmental, socio-economic and political factors.

\section{Insights, Lessons and Future Research}

This section has investigated the issues, and looked at emerging practice relating to the prioritisation of adaptation, and in particular the development of light-touch approaches for decision-making under uncertainty for developing countries. This recognises that the scoping and appraisal of adaptation is likely to become more important as climate finance becomes available and there is a greater focus on economic appraisal.

At the scoping phase of appraisal, there is considerable potential for using iterative adaptive management to help prioritise options based on the timing and phasing of adaptation. There are examples of such approaches starting to emerge with guidance and case studies.

At the detailed appraisal phase, particularly in relation to the new decision support tools that have emerged, there remains limited progress in developing more pragmatic (light-touch) versions, which can capture core concepts of decision making under uncertainty while maintaining a degree of economic rigour. Furthermore, there is some indication that there will need to be important differences in developing this light-touch applications between developed and developing countries.

Finally, future work to advance and to demonstrate light-touch, pragmatic approaches is needed, with a greater focus on ensuring they reflect - and are appropriate for - developing countries. This is identified as a future practical research priority. 


\section{VI: Final Discussion and Future Research}

This working paper has investigated a number of methodological challenges with adaptation appraisal in more detail, focusing on:

- Mainstreaming adaptation into development planning.

- The analysis and appraisal of building (adaptive) capacity and non-technical adaptation.

- The consideration of distributional effects.

- The phasing and prioritisation of adaptation and the application of light-touch approaches for decision making under uncertainty.

In each case a review has been undertaken, followed by an analysis of projects from the IDRC portfolio and wider literature, to provide insights and early lessons. As a general finding, the analysis has found a growing body of academic analysis in all of these areas, which provide useful information and insights. However, to date there has been little practical implementation, and where this has occurred, it has highlighted that more pragmatic and applied approaches are needed. Following from this, a number of future research activities are identified, with a focus on practical application.

For mainstreaming, there is a need for more policy-orientated research, advancing practical examples and ensuring that these processes are evaluated to provide learning, including through communities of practice and sharing of information and knowledge. Looking towards implementation, there will be a need for technical assistance and capacity building to support mainstreaming in practice.

For the appraisal of capacity building and socio-institutional adaptation options, there is a need to generate information from ex post evaluation on relevant capacity building and institutional strengthening/technical assistance interventions, for use in appraisal. This would also provide valuable information for monitoring and learning. There is also a need to consider lessons from the existing capacity building and institutional literature on how to design effective programmes, as well as to identify what additional components or aspects might be needed for the climate and adaptation context.

With respect to distributional effects, the paper finds that this issue is not being advanced consistently and effectively in the developing country context. There is a considerable need to consider the distributional issues - in both risk and adaptation assessment - and this is likely to need qualitative and semi-quantitative approaches (rather than the use of distributional weights: further work to develop and demonstrate these approaches is a priority.

Finally, further work is needed to advance and to demonstrate light-touch, pragmatic approaches to project and policy appraisal, with a greater focus on ensuring they reflect - and are appropriate for the developing country context.

In all these areas, it would be extremely valuable to support knowledge sharing and to advance communities of practice, through existing networks, particularly if these can align to existing adaptation policy and planning initiatives and link with decision-makers as well as researchers. 


\section{Bibliography}

ACIAR (2007). Impact assessment of capacity building and training: assessment framework and two case studies. Gordon J and Chadwick K. Australian Centre for International Agricultural Research Available at http://impact.cgiar.org/sites/default/files/pdf/76.pdf

ADB (1997). Guidelines for the Economic Analysis of Projects. Published by the ADB, Manilla.

Adhikari B. (2003). Property Rights and Natural Resources: Socio-Economic Heterogeneity and Distributional Implictions of Common Property Resource Management. South Asian Network for Development and Environmental Economics (SANDEE).

AFDB (2011). Climate Screening and Adaptation Review \& Evaluation Procedures. Booklet. Available at http://www.climateadaptation.cc/files/7213/5602/5312/CSS_Basics-En.pdf

Agrawala S, Moehner A, Hemp A, van Aalst M, Hitz S, Smith J, Meena H, Mwakifwamba SM, Hyera T, Mwaipopo OU (2003). Development and Climate Change in Tanzania: Focus on Mount Kilimanjaro (Environment Directorate and Development Co-operation Directorate, Organisation for Economic Co- operation and Development, Paris).

Ahmad, M., Siftain, H., and Iqbal, M. (2014). Impact of Climate Change on Wheat Productivity in Pakistan: A District Level Analysis. Climate Change Working Papers No. 1. Pakistan Institute of Development Economics, Islamabad, Pakistan.

Ahmad, M., Nawaz, M., , Muhammad Iqbal, M., and Amin Javed, S. (2014). Analysing the Impact of Climate Change on Rice Productivity in Pakistan. Climate Change Working Papers No. 2. Pakistan Institute of Development Economics, Islamabad, Pakistan.

Balasubramanian, R. and Selvaraj, K.N. (2003) Poverty, Private Property and Common Pool Resource Management: The Case of Irrigation Tanks in South India. SANDEE working papers, 2-03. Kathmandu.

Ballard, D, Black, D and Lonsdale, K (2013a). Initial Assessment of the UK's Adaptive Capacity for Responding to the Impacts of Climate Change. Report for Department for Environment, Food and Rural Affairs as part of the UK Climate Change Risk Assessment. Published 2013

Ballard, D, Bond, C, Pyatt, N, Lonsdale, K, Whitman, G.P., Dessai, S., Evans, M., Tweed, J.H. (2013b) PREPARE Barriers and enablers to organisational and sectoral adaptive capacity - qualitative study, Part of the PREPARE Programme of research on preparedness, adaptation and risk, Final Report for project ERG1211 by Ricardo-AEA for Defra. Report reference Ricardo-AEA/R/ED58163/PREPARE R1a/Issue 1.0.

Ballard, D (2014). CAFCA - Climate Adaptation Financing Coastal Areas. Method Paper.

Bayani-Arias, J. K. , Mendoza, M. E. T., , Ballaran, V.G., Dorado, R.A., and Burgos, B. M. (2013). Cost Benefit Analysis Research Report: Philippines. Building Capacity to Adapt to Climate Change in Southeast Asia. IDRC Grant No.: 106326-002

Belli, P. J. Anderson, H. Barnum, J. Dixon and. J-P. Tan (1998). Handbook on economic analysis of investment operations, World Bank, Washington DC.

Berge, R and Chambwera, M (2010). Beyond CBA. IIED briefing paper. Available at www.iied.org/pubs/display.php?o=17081IIED

Berkhout, F., Hertin, J. \& Gann, D.M.(2006). Learning to Adapt: Organisational Adaptation to Climate Change Impacts. Climatic Change, 78(1), pp.135-156.

Berrang-Ford L, Ford, JD, Paterson J. Are we adapting to climate change? Global Environmental Change 21 (2011) 25-33. doi:10.1016/j.gloenvcha.2010.09.012.p. 
Borja-Vega, C. and A. de la Fuente (2013). Municipal Vulnerability to Climate Change and Climate-Related Events in Mexico, Policy Research Working Paper No. 6417, The World Bank, Social Development Department,

Sustainable Development Network, April.

Cartwright, A., Blignaut,J., De Wit, M., Goldberg, K., Mander, M., O'Donoghue, S., and Debra Roberts, D (2013). Economics of climate change adaptation at the local scale under conditions of uncertainty and resource constraints: the case of Durban, South Africa. Environment and Urbanization 2013 25: 139. DOI: $10.1177 / 0956247813477814$

Chambwera M., J. Stage (2010). Climate change adaptation in developing countries: issues and perspectives for economic analysis, IIED publication.

Huang, C., Wang, J., and Huang, J., 2014. Policy Support, Social Capital and Farmers' Adaptation to Drought in Crop Production China, Global Environmental Change, 24: 193-202.

Clements (2013). The Value of Climate Services Across Economic and Public Sectors. Report to the United States Agency for International Development (USAID). It was prepared by Engility/International Resources Group (IRG). Available at http://www.climate-services.org/sites/default/files/CCRD-Climate-Services-Value-Report FINAL.pdf

Cimato, F. and M. Mullan (2010), "Adapting to Climate Change: Analysing the Role of Government", Defra Evidence and Analysis Series, Paper No. 1, Defra, London.

Daron, J (2016). Challenges in using a Robust Decision Making approach to guide climate change adaptation in South Africa. Climatic Change. Accepted.

Dasgupta, P,. Cost-Benefit Analysis for Drinking Water: A Study of River Mayur at Khulna, Bangladesh. Report. Report submitted to IIED.

Dasgupta, P.., Ghosh, P.K., RahmanR., and Khan M. S. A (2015). Chapter 9. Mapping gains and losses from the Mayur ecosystem.

De Bruin, K., Dellink, R. B., Ruijs, A., Bolwidt, L, van Buuren, A., Graveland, J., de Groot, R. S., Kuikman, P. J., Reinhard, S., Roetter, R. P., Tassone, V. C., Verhagen, A. and van Ierland, E. C. (2009b), 'Adapting to climate change in The Netherlands: an inventory of climate adaptation options and ranking of alternatives, Climatic change, 95, 23-45. DOI 10.1007/s10584-009-9576-4.

Department for International Development (2013). How to Note - Capacity Development. Available at https://www.gov.uk/government/publications/how-to-note-capacity-development.

Dehlavi, A., Groom, B., Grost, A. \& Zaman, F. 2015. Climate ChangeA daptation in the Indus Ecoregion: A Microeconometric Study of the Determinants, Impact, and Cost Effectiveness of Adaptation Strategies. WWF-Pakistan (Karachi).

Dessai S; and Hulme M (2007) Assessing the robustness of adaptation decisions to climate change uncertainties: A case study on water resources management in the East of England, Global Environmental Change, 17, pp.59-72. doi: 10.1016/j.gloenvcha.2006.11.005.

DFID (2010). How to note on capacity development. https://www.gov.uk/government/publications/how-to-notecapacity-development

DFID (2012). Guidance on measuring and maximising value for money in social transfer programmes -second edition.

DFID (UK Department for International Development) (2014), Early Value-for-Money Adaptation: Delivering VfM Adaptation using Iterative Frameworks and Low-Regret Options, DFID, London. Available at www.vfmadaptation.com 
DFID (2015). Tanzania Climate Change Institutional Strengthening Programme. Business Case. Development tracker.

EA (2009). Thames Estuary 2100. Managing flood risk through London and the Thames estuary. TE2100 Plan Consultation Document April 2009

EA (2011). TE2100 Strategic Outline Programme (Environment Agency, 2011). Published by: Environment Agency.

ECONADAPT (2015). "The Costs and Benefits of Adaptation", results from the ECONADAPT Project, ECONADAPT consortium, http://econadapt.eu/.

Guerrero Escobar, S, Juárez Torres, M and López Cabrera, J. A.. Corn Production, Cultivated Area And Price Responses To Climate Change In Mexico. Report to the Latin American and Caribbean Environmental Economics Program (LACEEP).

Fankhauser, S., Ranger,N., Colmer, J., Fisher, S., Surminski, S., Stainforth, D and Williamson, A. (2013). An Independent National Adaptation Programme for England. Policy Brief. Published by Centre for Climate Change Economics and Policy and Grantham Research Institute on Climate Change and the Environment, March 2013.

Frontier (2013). The Economics of Climate ResilienceCA0401 Synthesis Report March 2013.

FCFA (2014). Using climate information to achieve long-term development objectives in Rwanda. Future Climate For Africa: Rwanda Pilot. Available at http://futureclimateafrica.org/wp-

content/uploads/2015/02/FCFA_PolicyBrief_Rwanda_.pdf

FCFA (2015). Future Climate For Africa: Rwanda Pilot: Inside Story: FCFA Applied Research Fund: Economics, Political Economy and Behavioural Science of Accounting for Long-term Climate in Decision Making Today.

FDRE (2015). Ethiopia's Climate-Resilience Strategy Agriculture. Federal Democratic Republic of Ethiopia, Environmental Protection Authority.

Gustavo A. Garcia Lopez and Sergio Villamayor Tomás (2015). Understanding individual and community-based adaptations to climate change: Factors influencing responses to drought in Mexican irrigation communities. Report to the Latin American and Caribbean Environmental Economics Program (LACEEP).

GoR (2012). FONERWA Operational Manual. Available at

http://static1.squarespace.com/static/537dea6de4b00847c54026be/t/53f1df74e4b0439bf8d475cd/140836030890 1/fonerwa_operationalmanual.pdf

Hallegatte, S, (2011) How Economic Growth and Rational Decisions Can Make Disaster Losses Grow Faster Than Wealth. Policy Research Working Paper 5617. World Bank, Washington

Hallegatte, S., Shah, A., Lempert, R., Brown, C. and Gill, S. (2012). Investment Decision Making Under Deep Uncertainty: Application to Climate Change. Policy Research Working Paper 6193. World Bank.

Herderberg, A.C. (1978). On the use of distributional weights in social cost-benefit analysis. Journal of political Economy 86 (2).

Hinkel, J. and A. Bisaro (2013), "Methodological choices in problem-oriented adaptation research: a diagnostic framework", Regional Environmental Change,

HMT (2011). The Green Book. Appraisal and Evaluation in Central Government. London: Her Majesty's Treasury.

HM Government (2013), The National Adaptation Programme Report: Analytical Annex, Economics of the National Adaptation Programme, HM Government, London.

HMT, 2009. Accounting for the Effects of Climate Change. June 2009. Supplementary Green Book Guidance, Available at 
http://www.hm-treasury.gov.uk/data_greenbook_supguidance.htm\#Adaptation_to_Climate_Change

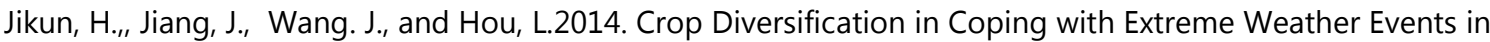
China, Journal of Integrative Agriculture, 13(4): 677-686.

Jikun, H. and Wang, Y.2014. Financing Sustainable Agriculture Under Climate Change, Journal of Integrative Agriculture, 13(4): 698-712.

Hunt, A. and Ferguson, J. (2015). Distributional impacts: Intranational, international and inter-temporal aspects of equity in adaptation. In Routledge Handbook Of The Economics Of Climate Change Adaptation. Edited by Anil Markandya, Ibon Galarraga and Elisa Sainz de Murieta. Published by Routledge.

International Livestock Research Institute (2006) Mapping Climate Vulnera- bility and Poverty in Africa (Int Livestock Res Inst, Nairobi).

Jayachandran S, (2006). "Selling Labor Low: Wage Responses to Productivity Shocks in Developing Countries," Journal of Political Economy, University of Chicago Press, vol. 114(3), pages 538-575, June.

IPCC (2012), Managing the Risks of Extreme Events and Disasters to Advance Climate Change Adaptation, A Special Report of Working Groups I and II of the Intergovernmental Panel on Climate Change, Cambridge University Press, Cambridge and New York.

IPCC (Intergovernmental Panel on Climate Change) (2014), Climate Change 2014: Impacts, Adaptation, and Vulnerability, Contribution of Working Group II to the Fifth Assessment Report of the Intergovernmental Panel on Climate Change, Cambridge University Press, Cambridge and New York.

Javed, S, A., Ahmad, M., and Iqbal, M. (2014). Impact of Climate Change on Agriculture in Pakistan: A District Level Analysis. Climate Change Working Papers No. 3. Pakistan Institute of Development Economics, Islamabad, Pakistan.

Johansson-Stenman O. (2005). Distributional weights in cost-benefit analysis - should we forget about them?, in Land Economics.

Jones, L., Dougill, A. Jones, R.G.,, Steynor, A., Watkiss ,P., Kane, C., Koelle, B., Moufouma-Okia, W.., Padgham, J., Ranger, N, Roux,J-P., Suarez, P., Tanner, T., \& Vincent, K. (2015). Ensuring climate information guides long-term development. Nature Climate Change 5, 812-814 (2015) doi:10.1038/nclimate2701

Klein, R.J.T., et al., (2014), Adaptation opportunities, constraints, and limits. In: Climate Change 2014: Impacts, Adaptation, and Vulnerability. Part A: Global and Sectoral Aspects. Contribution of Working Group II to the Fifth Assessment Report of the Intergovernmental Panel on Climate Change.

Learning Network on Capacity Development (LenCD). How to Formulate Capacity Indicators (http://www.lencd.org/learning/howto-indicators).

Least Developed Countries (LDC) Expert Group. 2012. National Adaptation Plans. Technical guidelines for the national adaptation plan process. Bonn: UNFCCC secretariat. Bonn, Germany. December 2012. Available at: http://unfccc.int/NAP

Lempert R.J. and Groves, D.G (2010). Identifying and evaluating robust adaptive policy responses to climate change for water management agencies in the American west. Technological Forecasting \& Social Change,77,960-974.

Lempert R, Kalra N (2011) Managing Climate Risks in Developing Countries with Robust Decision Making. World Resources Report Uncertainty Series. Available at http://www.worldresourcesreport.org/

Lunduka, R.W., Bezabih, M. and Chaudhury, A. (2012). Stakeholder-focused cost benefit analysis in the water sector: A synthesis report.

International Institute for Environment and Development (IIED), London, UK. 
Macauley, M. K. (2010) Climate Adaptation Policy: The Role and value of Information. Resources for the Future. May 2010, Issue Brief 10-10. The Public Weather Service's contribution to the UK economy", Met Office, May 2007.

Madrigal-Ballestero, R., and Naranjo, M-A (2013). Adaptive capacity, drought and the performance of communitybased drinking water organizations in Costa Rica. Report to the Latin American and Caribbean Environmental Economics Program (LACEEP).

MacMahon G. (1997). Applying Economic Analysis to Technical Assistance Projects, World Bank, Volume 1749,

Mechler, R. (2005). "Cost-benefit analysis of natural disaster risk management in developing countries". Deutsche Gesellschaft für Technische Zusammenarbeit (GTZ).Arbeitskonzept. Eschborn, Germany.

MoEF (2009). Bangladesh Climate Change Strategy and Action Plan (BCCSAP). Ministry of Environment and Forestry. Government of the People's Republic of Bangladesh.Morton J. (2007). The impact of climate change on smallholder and subsistence agriculture, Natural Resources Institute, University of Greenwich, Kent ME4 4TB, United Kingdom. Edited by William Easterling, Pennsylvania State University, University Park, PA, and accepted by the Editorial Board September 26, 2007.

Moser, S.C. and J. Ekstrom (2010), "A framework to diagnose barriers to climate change adaptation", Proceedings of the National Academy of Sciences of the United States of America, Vol. 107(51), http://dx.doi.org/10.1073/pnas.1007887107.

O'Brien. K. (2012), "Global environmental change II: From adaptation to deliberate transformation", Progress in Human Geography, Vol. 36 (5), http://dx.doi.org/10.1177/0309132511425767.

OECD (2009), Integrating Climate Change Adaptation into Development Co-operation: Policy Guidance, OECD Publishing, Paris, http://dx.doi.org/10.1787/9789264054950-en.

OECD (2012), Greening Development: Enhancing Capacity for Environmental Management and Governance, OECD Publishing. http://dx.doi.org/10.1787/9789264167896-en.

OECD (2014). Climate Resilience in Development Planning: Experiences in Colombia and Ethiopia. OECD Publishing, Paris.

OECD (2015). 'Climate Change Risks and Adaptation: Linking Policy and Economics'. OECD Publishing, Paris.

Oxford Policy Management (2006) Developing Capacity? An Evaluation of DFID-funded Technical cooperation for Economic Management in Sub-Saharan Africa - Synthesis Report.

Oxford Policy Management (2012) Multi-Stakeholder Evaluation of Public Sector Governance Reform - Draft Synthesis Report

Pacay et al. Use of empirical evidence for the construction of natural disasters risks indexes in Honduras.

Parry, M., Arnell, N., Berry, P., Dodman, D., Fankhauser, S., Hope, C., Kovats, S., Nicholls, R., Satterthwaite, D., Tiffin, R., Wheeler, T. (2009), Assessing the costs of Adaptation to climate change. A review of the UNFCCC and other recent estimates. International Institute for Environment and Development and Grantham Institute for Climate Change, London.

Perrels, A., Harjanne, A., Nurmi, V., Pilli-Sihvola, K.,, Heyndricx, C., and Stahel, A. (2013). TopDAD. D2.2-Sector specific and generic impacts of enhanced weather and climate services in a changing climate. Available from http://www.topdad.eu/

Ranger, N. (2013) Topic Guide. Adaptation: Decision Making Under Uncertainty.

Ranger, N. and Garbett-Shiels, S. (2011). How can decision-makers in developing countries incorporate uncertainty about future climate risks into existing planning and policy-making processes? Centre for Climate 
Change Economics and Policy Grantham Research Institute on Climate Change and the Environment in collaboration with the World Resources Report.

Nyda, C., Hoeurn, C., and Naret, H (2013). Climate Resilience in Agriculture: Benefits and Costs Analysis of Adaptation Options to Address Drought in Cambodia. Report to Building Capacity to Adapt to Climate Change in Southeast Asia. IDRC Grant No: 106326-003.

Reid, H., et al. (2008). Climate change impacts on Namibia's natural resources and economy. Climate Policy 8 : 452-466.

Rios et al. Present and future of the water deposits in Calakmul, Mexico: analysis of the behaviour of inhabitants facing climate change.

Ranger, N. Harvey A. \& Garbett-Shiels, S.L. (2014) Safeguarding development aid against climate change: evaluating progress and identifying best practice. Development in Practice, 24:4, 467-486

Reeder, T and Ranger, N (2011). "How do you adapt in an uncertain world? Lessons from the Thames Estuary 2100 project." World Resources Report, Washington.

Republic of Rwanda (2012) Economic Development And Poverty Reduction Strategy 2013 - 2018. Published by the Republic of Rwanda, Kigali, Rwanda. http://www.edprs.rw/content/edprs-2

RGS (2014). Zanzibar Climate Change Strategy and Action Plan (2014). Revolutionary Government of Zanzibar.

RoR (2011). Rwanda Green Growth and Climate Resilience (National Strategy for Climate Change and Low Carbon Development), 2011. Republic of Rwanda.

RoR (2012). Economic Development and Poverty Reduction Strategy (2013 - 2018): Shaping Our Development. Republic of Rwanda.

RoR (2013). Strategic Plan for the Transformation of Agriculture in Rwanda Phase III. Ministry of Agriculture and Animal Resources, Republic of Rwanda. July 2013.

RoR (2014). Ministry of Agriculture and Animal Resources (MINAGRI). Rwanda, 2nd Agriculture Sector Investment Plan (ASIP-2) Period: 01.07. 2013 - 30.06.2018 (Fiscal years 2013/14 to 2017/18).

Roy J. (2006). Estimating the Economic Benefits of Arsenic Removal in India: A Case Study from West Bengal. South Asian Network for Development and Environmental Economics (SANDEE).

Skoufias M. (2011), The Poverty Impacts of Climate Change, Poverty Reduction And Economic Management Network (PREM), March 2011, Number 15, The World Bank.

Stern, N. 2006. The Economics of Climate Change: The Stern Review. Cambridge University Press, Cambridge, UK. Thampanishvong, K. (2015). Analyzing the Determinants of Farmers' Adaptation to Climate Change in the Chao Phraya River Basin. Paper to IDRC.

Dung The, B. (2014) Project Completion Report. Integrated Synthesis. Building Capacity to Adapt to Climate Change In Southeast Asia. IDRC Grant No.: 106326

Dung The. B. and Duc Tinh, B (2014). Cost-Benefit Analysis of Flood Adaptations in the An Xuan Tributary Basin, Thua Thien Hue, Vietnam. EEPSEA 2014-RR5. Published by the Economy and Environment Program for Southeast Asia (EEPSEA) EEPSEA Philippines Office, WorldFish Philippines Country Office, SEARCA bldg., College, Los Baños, Laguna, 4031 Philippines. ISBN: 978-971-9994-43-5.

Thureson D. (2012). Avoiding path dependence of distributional weights. Lessons from climate change economic assessment. Working paper 8/2012. Swedish Business School. 
Tol, R., and Yohe, G., (2006) The weakest link hypothesis for adaptive capacity: an empirical test. Available at http://www.mi.uni-hamburg.de/fileadmin/fnu-files/publication/working-papers/weakestlinkwp.pdf

UKCIP (2006). Identifying adaptation options. UK Climate Impacts Programme. 2008.

Downing, T.E. (2012). Views of the frontiers in climate change adaptation economics. WIREs Clim Change 2012. doi: 10.1002/wcc.157.

UKCIP (2008). The UKCIP Adaptation Wizard V 2.0. UKCIP, Oxford

UNDP (United Nations Development Programme)/UNEP (United Nations Environment Programme) (2011), Mainstreaming Climate Change Adaptation into Development Planning: A Guide for Practitioners, UNDP-UNEP Poverty-Environment Initiative, Nairobi.

UNEP 2014. The Adaptation Gap Report 2014. United Nations Environment Programme (UNEP), Nairobi. ISBN: 978-92-807-3428-7

URT (2012) Tanzania national climate change strategy (2012). United Republic of Tanzania, Vice President's office.

URT (2014). Tanzania Agriculture Climate Resilience Plan, 2014-2019. Published by the Ministry of Agriculture, Food Security and Cooperatives (MAFC), United Republic of Tanzania, 2014.

Vivid Economics. (2010). Promoting Economic Growth when the Climate is Changing.

Vincent, K. 2007. Uncertainty in adaptive capacity and the importance of scale. Global Environment Change 17: 12-24.

Wang, Y, Huang, J. and Wang, J (2014).Household and Community Assets and Farmers' Adaptation to Extreme Weather Event: the Case of Drought in China. Journal of Integrative Agriculture, 13(4): 687-697.

Wang, J., Huang, J., Zhang, L. and Li, Y. (2013). Impacts of Climate Change on Crop Net Revenue in North and South Regions of China, China Agricultural Economic Review, 6(3), 358-378.

Wang, J., Yang, Y and Huang, J. (2015). Information Provision, Policy Support, and Farmers' Adaptive Responses against Drought: An Empirical Study in the North China Plain, submitted to Ecological Modelling. 10.1016/j.ecolmodel.2014.12.013.

Watkiss P. (2011) Aggregate economic measures of climate change damages: explaining the differences and implications, WIREs Climate Change, Volume 2, May/June 2011.

Watkiss, P. and A. Hunt, 2011: Method for the UK Adaptation Economic Assessment (Economics of Climate Resilience). Final Report to Defra. May 2011. Deliverable 2.2.1

Watkiss, P. et al. (2014), "The use of new economic decision support tools for adaptation assessment: A review of methods and applications, towards guidance on applicability", Climatic Change, http://dx.doi.org/10.1007/s10584-014-1250-9.

Watkiss, P., Benzie, M, and Klein, R. J. T (2015). The complementarity and comparability of climate change adaptation and mitigation. WIREs Clim Change 2015, 6:541-557. doi: 10.1002/wcc.368

Watkiss, P (2015). A review of the economics of adaptation and climate-resilient development. Centre for Climate Change Economics and Policy Working Paper No. 231/ Grantham Research Institute on Climate Change and the Environment Working Paper No. 205. Available at http://www.lse.ac.uk/GranthamInstitute/wpcontent/uploads/2015/09/Working-Paper-205-Watkiss.pdf. Accessed January 2016.

Weiss and Fujimura (2000). Integration of Poverty Impact in Project Economic analysis: Issues in Theory and Practice. EDRC Methodology Series No. 2 (Asian Development Bank 2000). 
Wilby, Robert L. (2012). Frameworks for delivering regular assessments of the risks and opportunities from climate change: An independent review of the first UK Climate Change Risk Assessment. Final Report to the Committee on Climate cange. 18 June 2012.

Wilby, R.L and Keenan, R (2012). Adapting to flood risk under climate change. Progress in Physical Geography. 36(3) 348-378

World Bank (2010). Tanzania Urban Local Government Strengthening Programme. Technical Anaysis. World Bank Group. Available at http://www-

wds.worldbank.org/external/default/WDSContentServer/WDSP/IB/2012/12/05/000356161_20121205004440/Ren dered/PDF/NonAsciiFileName0.pdf

World Bank (2000). Ex Ante Economic Analysis In Agricultural Knowledge \& Information Systems (Akis) Projects . Good Practice Note (2000). Available at http://www-

wds.worldbank.org/external/default/WDSContentServer/WDSP/IB/2012/08/03/000333037_20120803023233/Ren dered/PDF/208810DWPOREPLONote0Exante0Analysis.pdf

World Bank (1999) Project Appraisal Document On a Proposed Adaptable Program Credit To the Republic of Mozambique In support of the first phase of an Agricultural Sector Public Expenditure Program (proagri).Available at http://www-

wds.worldbank.org/external/default/WDSContentServer/WDSP/IB/2000/08/02/000094946_99031910572679/Ren dered/PDF/multi_page.pdf

World Bank (2005). Operations Evaluation Department (2005) Capacity Building in Africa: An Evaluation of World Bank Support.

World Bank (2011). Natural Hazards, UnNatural Disasters, The Economics of Effective Prevention. World Bank, Washington.

World Bank (2012). A Cost Effective Solution to Reduce Disaster Losses in Developing Countries: HydroMeteorological Services, Early Warning, and Evacuation. Stéphane Hallegatte. Policy Research Working Paper 6058.

World Bank (2013). Energy sector capacity building project. http://wwwwds.worldbank.org/external/default/WDSContentServer/WDSP/IB/2013/03/08/000442464_20130308101108/Ren dered/PDF/691350PAD0P12600fficial0Use0Only090.pdf

World Bank (2013). "Weather, Climate and Water Hazards and Climate Resilience: Effective Preparedness through National Meteorological and Hydrological Services. 